\title{
The anticonvulsive Phenhydan suppresses extrinsic cell death
}

\author{
Caroline Moerke ${ }^{1}$ Isabel Jaco ${ }^{2} \cdot$ Christin Dewitz $^{1} \cdot$ Tammo Müller $^{1} \cdot$ Annette V. Jacobsen $\mathbb{1}^{3,4} \cdot$ Jérémie Gautheron ${ }^{5}$. \\ Jürgen Fritsch ${ }^{6}$ Jessica Schmitz ${ }^{7}$ Jan Hinrich Bräsen ${ }^{7}$. Claudia Günther ${ }^{8}$ - James M. Murphy $\mathbb{1}^{3,4}$. \\ Ulrich Kunzendorf ${ }^{1} \cdot$ Pascal Meier $^{2} \cdot$ Stefan Krautwald $\mathbb{B}^{1}$
}

Received: 30 May 2018 / Revised: 30 October 2018 / Accepted: 30 October 2018 / Published online: 15 November 2018

(c) The Author(s) 2018. This article is published with open access

\begin{abstract}
Different forms of regulated cell death-like apoptosis and necroptosis contribute to the pathophysiology of clinical conditions including ischemia-reperfusion injury, myocardial infarction, sepsis, and multiple sclerosis. In particular, the kinase activity of the receptor-interacting serine/threonine protein kinase 1 (RIPK1) is crucial for cell fate in inflammation and cell death. However, despite its involvement in pathological conditions, no pharmacologic inhibitor of RIPK1-mediated cell death is currently in clinical use. Herein, we screened a collection of clinical compounds to assess their ability to modulate RIPK1-mediated cell death. Our small-scale screen identified the anti-epilepsy drug Phenhydan as a potent inhibitor of death receptor-induced necroptosis and apoptosis. Accordingly, Phenhydan blocked activation of necrosome formation/activation as well as death receptor-induced NF- $\mathrm{KB}$ signaling by influencing the membrane function of cells, such as lipid raft formation, thus exerting an inhibitory effect on pathophysiologic cell death processes. By targeting death receptor signaling, the already FDA-approved Phenhydan may provide new therapeutic strategies for inflammation-driven diseases caused by aberrant cell death.
\end{abstract}

These authors contributed equally: Caroline Moerke and Isabel Jaco

Edited by E. Baehrecke

Electronic supplementary material The online version of this article (https://doi.org/10.1038/s41418-018-0232-2) contains supplementary material, which is available to authorized users.

Stefan Krautwald

krautwald@nephro.uni-kiel.de

1 Department of Nephrology and Hypertension, University Hospital Schleswig-Holstein, 24105 Kiel, Germany

2 Toby Robins Research Centre, Institute of Cancer Research, London SW3 6JB, UK

3 The Walter and Eliza Hall Institute of Medical Research, Parkville, VIC 3052, Australia

4 Department of Medical Biology, University of Melbourne, Parkville, VIC 3052, Australia

5 Université Pierre et Marie Curie, UMR_S 938, Inserm, 75012 Paris, France

6 Institute for Clinical Microbiology and Hygiene, University of Regensburg, 93053 Regensburg, Germany

7 Department of Pathology, University of Hannover, 30625 Hannover, Germany

8 Department of Medicine 1, Friedrich-Alexander-University, 91052 Erlangen, Germany

\section{Introduction}

Cell death plays a significant role in a variety of human diseases, determining the extent of tissue destruction and, in turn, organ function [1]. The past decade has witnessed significant expansion of our understanding of regulated cell death beyond apoptosis. Programmed necrosis such as necroptosis, which is characterized by plasma membrane rupture and the release of intracellular contents, is an alternate cell death pathway that has been demonstrated to eliminate cells when caspase activity is limited [2]. Furthermore, it has been established that receptor-interacting serine/threonine protein kinase (RIPK) 1 , its related kinase RIPK3, and its substrate Mixed lineage kinase domain-like protein (MLKL) constitute the core of the necroptosis machinery, termed the necrosome [3-6]. RIPK1 can be activated by multiple triggers, including signaling by members of the TNF family of cytokines such as TNF $\alpha$, TLR3 and 4, Interferon receptors, and certain pathogens [7-9]. RIPK1-mediated cell death is best characterized for TNF receptor 1 (TNFR1), and phosphorylation of the necrosome components RIPK1, RIPK3, and MLKL at different sites is a hallmark of the induction of necroptosis [10]. However, cell death is not the only signaling outcome for this receptor; in fact, NF- $\mathrm{KB}$ activation is often the dominant response of death receptors. 
Increasing evidence from genetic and pharmacologic analyses has shown that RIPK1-induced cell death is a driver of inflammation and contributes to the progression of many cell death-associated conditions, such as myocardial infarction, stroke, sepsis, viral infections, hepatitis, and ischemia-reperfusion injury (IRI), which is an unavoidable consequence after kidney transplantation. Of course, the development of selective therapeutics for all these disorders would be of overriding relevance. However, no pharmacologic inhibitor of RIPK1-mediated cell death is currently in clinical use.

The highly efficient RIPK1 inhibitor 5-(indol-3-ylmethyl)-3-methyl-2-thio-hydantoin, herein termed necrostatin1 (Nec-1), was identified in 2005 as the first compound to block necroptotic cell death in human and murine cells [11]. It inhibits the kinase activity of RIPK1, and its protective effect against different cell death scenarios was widely interpreted as confirmation of the occurrence of necroptosis. However, because of its short plasma half-life, in vivo studies examining the therapeutic effects of Nec-1 are extremely scarce. Nec-1 was later discovered to be chemically identical to methyl-thiohydantoin-tryptophan, an inhibitor of the potent immunomodulatory enzyme indoleamine 2,3-dioxygenase (IDO) [12], which means that Nec-1 can exert effects on the immune system that are independent of the inhibition of the kinase activity of RIPK1. Nec-1s, an enhanced stable analogue of Nec-1 that does not target IDO, has a much longer half-life in vivo, and is able to interfere with RIPK1-dependent processes, was developed [12]. Necrostatins fail to block necroptosis in the absence of RIPK1 [13], eliminating the therapeutic application of Nec-1s for RIPK1-independent necroptosis. However, a further RIPK1 inhibitor, GSK2982772, has been developed and is currently undergoing Phase-IIa clinical trials for the treatment of inflammatory diseases such as psoriasis and inflammatory bowel disease [14].

Investigators have proposed that RIPK3 represents a more promising target in this scenario of regulated cell death: it is assumed that suppression of the necroptotic pathway at the level of RIPK3 rather than RIPK1 will be more specific and offer greater therapeutic benefits. Indeed, pharmacologic inhibitors that target the kinase function of RIPK3, such as the small-molecule inhibitors GSK'843, GSK'872, GSK'840, dabrafenib, and ponatinib, have been crucial in demonstrating the importance of RIPK3 kinase activity for necroptosis $[7,15,16]$. Nevertheless, high doses of some of these drugs can induce RIPK3-dependent apoptosis, which is consistent with the observation that mice that express D161N RIPK3, a catalytically inactive form of RIPK3, die during embryogenesis [17], likely owing to an inability to suppress RIPK1-directed cell death allosterically [18]. These characteristics limit the potential of these inhibitors as therapeutic drugs for the suppression of regulated cell death. However, mice that express an alternate kinase-dead RIPK3 protein harboring a different point mutation, K51A, develop normally and survive to adulthood [19], which suggests that pharmacologic suppression of RIPK3 kinase activity without inducing apoptosis is feasible.

Necrosulfonamide (NSA), a cell-permeable acrylamide compound that inhibits human, but not murine, MLKL adaptor function via covalent modification of $\mathrm{C} 86$, has been successfully used to block necroptosis in vitro [6]. However, NSA contains a reactive moiety and is therefore highly promiscuous. For this reason, no clinical trials have been registered to evaluate its efficacy in an in vivo setting to date.

All of these promising inhibitors of the necrosome components RIPK1, RIPK3, and MLKL lack legal approval, which precludes their application for preclinical RIPK1-mediated diseases and reduces their therapeutic value in patients. Thus, we investigated whether drugs already approved and in clinical use were suited to the inhibition of regulated cell death processes. The underlying rationale is that the pharmacokinetics, side effects and safety profiles of such FDA-approved drugs are already well documented for therapeutic applications. The drugs examined in this study were considered independently of their current clinical applications, and their effects were compared with those of the potent RIPK1 kinase inhibitor Nec1s. Our data identify the mechanisms of Phenhydan mediated prevention of death receptor-induced regulated cell death and indicate that an inhibitor of cell deathassociated diseases is readily available for clinical application.

\section{Results}

To identify an FDA-approved drug that could be used for the treatment of pathophysiologic cell death processes, we selectively screened a small set of clinically approved compounds. In particular, we focused on drugs that are structurally related to Nec-1. To this end, we first tested the unsubstituted heterocyclic aromatic compound imidazole and its derivative hydantoin. We found that these exhibited no inhibitory effect on necroptosis in a range of necroptosissensitive cell lines (Fig. 1a-d). Next, we focussed on heterocyclic compounds, which constitute nearly $70 \%$ of active pharmaceuticals [20]. Particularly, we tested the effect of barbiturates, which are a class of drugs that produce effects ranging from mild sedation to anesthesia and are used to treat acute convulsive episodes requiring emergency intervention. Intriguingly, barbiturates such as Brevimytal and Luminal $^{\oplus}$ delayed but did not inhibit TNF-induced and RIPK1-mediated cell death in murine L929 cells (Fig. 1e, f). 
A

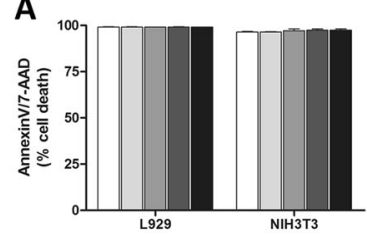

C

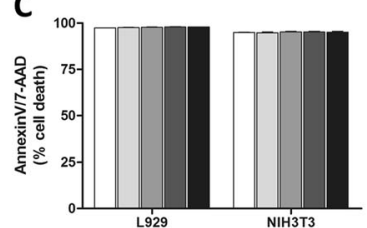

\section{$\square T z$}

$\square T Z+0.10 \mathrm{mM}$ imidazole $\square T Z+0.25 \mathrm{mM}$ imidazole D $T Z+0.50 \mathrm{mM}$ imidazole

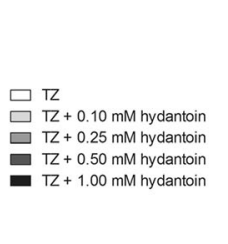

E

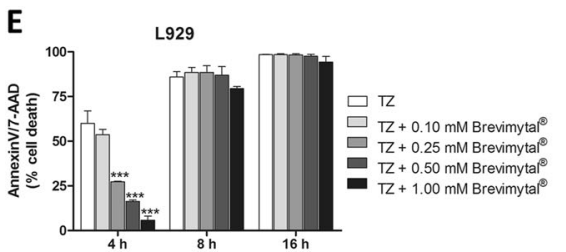

$\mathbf{F}$

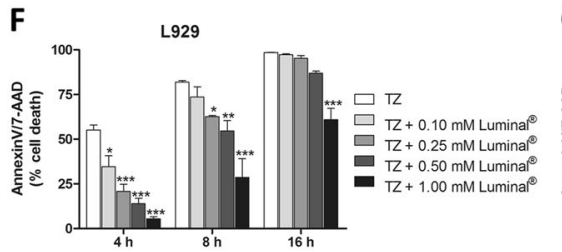

B

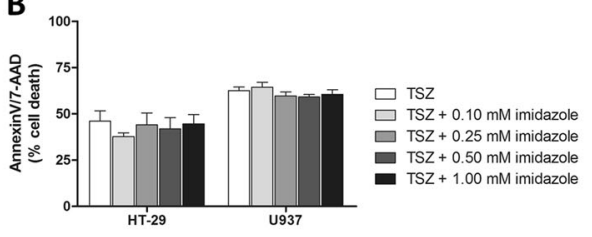

D

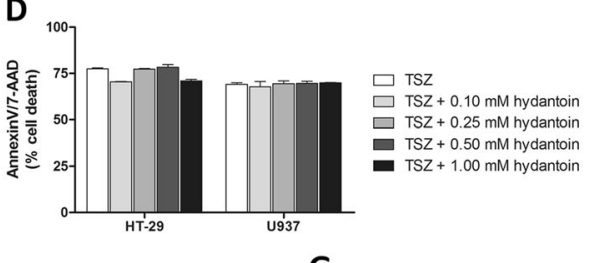

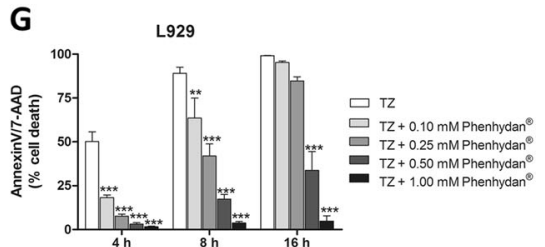

Fig. 1 Representative selection of imidazole and hydantoin derivatives based on their inhibitory effect in the course of RIPK1-dependent cell death. a, c Murine L929 and NIH3T3 cells were stimulated at $37^{\circ} \mathrm{C}$ for $16 \mathrm{~h}$ with $100 \mathrm{ng} / \mathrm{ml} \mathrm{TNF} \alpha+25 \mu \mathrm{M} \mathrm{zVAD}$ (TZ) in the absence or presence of different concentrations (as indicated) of unsubstituted imidazole and its derivative hydantoin, respectively. b, d For the induction of RIPK1-dependent necroptosis, human HT-29 and U937 cells were stimulated at $37^{\circ} \mathrm{C}$ for $16 \mathrm{~h}$ with $100 \mathrm{ng} / \mathrm{ml} \mathrm{TNF} \alpha+1 \mu \mathrm{M}$ SMAC mimetic SM164 $+25 \mu \mathrm{M}$ zVAD (TSZ) in the absence or

presence of the indicated amounts of imidazole and hydantoin. In each case, aromatic compounds were added $30 \mathrm{~min}$ before the induction of necroptosis. (E-G) L929 fibroblasts were stimulated at $37^{\circ} \mathrm{C}$ for 4,8 , and $16 \mathrm{~h}$ with $100 \mathrm{ng} / \mathrm{ml} \mathrm{TNF} \alpha+25 \mu \mathrm{M} \mathrm{zVAD}$ (TZ) in the absence or presence of Brevimytal ${ }^{\oplus}$ (e), Luminal ${ }^{\varpi}$ (f), or Phenhydan (g). Each drug was added $30 \mathrm{~min}$ before TZ stimulation. Necroptotic cell death was quantified by FACS analysis using 7-amino-actinomycin D and phosphatidylserine accessibility (Annexin $\mathrm{V}$ staining) as markers. Graphs show the mean \pm SEM; $n=4$ independent experiments

While Luminal delayed necroptosis, the more potent structural analogue phenytoin (Phenhydan'), which is widely used as antiepileptic, as well as in a broad spectrum of neurologic disorders [21], protected murine L929 cells from TNF-induced cell death in a dose-dependent manner, and for longer time points (Fig. 1g). Phenhydan not only inhibited RIPK1-mediated cell death in L929 cells but also in murine NIH3T3 as well as human HT-29, and U937 cells, expanding this observation to multiple cell types and species (Fig. 2a-d). In contrast to Phenhydan, a class of related benzodiazepines and benzodiazepine derivatives with an imidazole structure, such as Tavor and Dormicum ${ }^{\circ}$, did not exhibit any detectable effect on TNF-mediated cell death (data not shown), suggesting that the observed cell death suppression is specific to Phenhydan (all substances described and tested in this work, including their structural formulae, are listed in Supplementary Table 1).

Consistent with the notion that Phenhydan provides protection from RIPK1-mediated cell death, we found that Phenhydan ${ }^{\oplus}$ treatment suppressed phosphorylation and activation of RIPK1 (p-S166), RIPK3 (p-S227 in human and p-T231/S232 in murine cells) and MLKL (p-S358 in human and p-S345 in murine cells) in these cells (Fig. 2ad). The inhibitory properties of Phenhydan on TNFinduced cell death were also evident in primary cells such as bone marrow-derived macrophages (BMDCs) and mouse

embryonic fibroblasts (MEFs) (Supplementary Fig. 1). The protective effect of Phenhydan in TNF-induced cell death was found to be as potent as that of the laboratory established but not FDA-approved inhibitors Nec-1s (RIPK1), GSK'872 (RIPK3) and GW806742X (murine MLKL) [22]. Accordingly, we evaluated and illustrated the potent effect of Phenhydan in TZ-induced cell death and directly compared its effects with the aforementioned commercially available inhibitors (Supplementary Fig. 2).

Since Phenhydan suppressed auto-phosphorylation of S166 in RIPK1 following TNF treatment, our data suggest that Phenhydan suppresses early activation of RIPK1 in the TNF receptor signaling complex-I, and that Phenhydan ${ }^{\circ}$ might suppress TNFR1-signaling in general. Therefore, we evaluated whether Phenhydan affects TNF-induced NF- ${ }^{\circ} B$ signaling. Treatment of primary MEFs with TNF in the presence and absence of Phenhydan demonstrated that sequential phosphorylation of IкB $\alpha$, p65/RelA, p38 MAPK, MAPKactivated protein kinase-2 (MK2), and JNK after TNF stimulation was largely suppressed by Phenhydan (Fig. 3a). This strongly suggests that Phenhydan interferes with TNFR1 signaling. To test whether Phenhydan affects the recruitment of RIPK1 into TNF receptor signaling complex-I, we stimulated cells with TNF and isolated complex-I. As shown in Fig. 3b, Phenhydan decisively reduced the recruitment and ubiquitylation of RIPK1 in complex-I. 
A

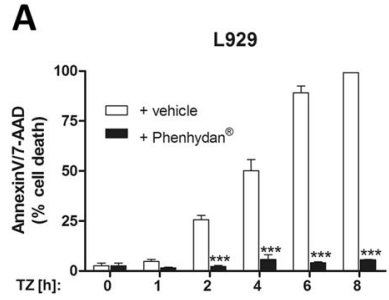

C

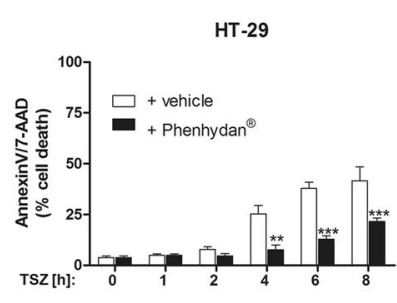

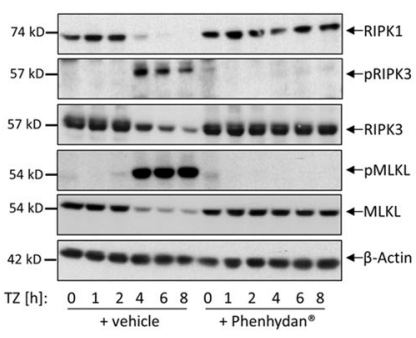

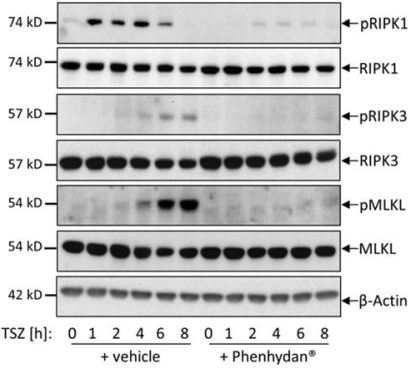

+ vehicle + Phenhydan ${ }^{\circ}$

Fig. 2 Species-independent confirmation of the inhibitory properties of Phenhydan in the course of necroptosis. Each probe was split for FACS analysis (left) and corresponding western blotting (right). a Murine L929 and murine NIH3T3 cells were stimulated at $37^{\circ} \mathrm{C}$ for up to $8 \mathrm{~h}$ with $100 \mathrm{ng} / \mathrm{ml} \mathrm{TNF} \alpha+25 \mu \mathrm{M} \mathrm{zVAD}$ (TZ) in the absence or presence of $1 \mathrm{mM}$ Phenhydan . For the induction of necroptosis, human HT-29 and human U937 cells were stimulated at $37^{\circ} \mathrm{C}$ for up to $8 \mathrm{~h}$ with $100 \mathrm{ng} / \mathrm{ml} \mathrm{TNF} \alpha+1 \mu \mathrm{M}$ SMAC mimetic SM164 $+25 \mu \mathrm{M}$ zVAD (TSZ) in the absence or presence of $1 \mathrm{mM}$ Phenhydan, wherein the drug Phenhydan ${ }^{\circledR}$ was added 30 min before the induction of necroptosis. Necroptotic cell death was quantified by FACS analysis using 7-amino-actinomycin D and phosphatidylserine accessibility

Furthermore, subsequent, time-dependent recruitment of cIAP1 and SHARPIN to the TNFR1 complex upon the addition of TNF was markedly diminished in the presence of Phenhydan $^{\circ}$ (Fig. 3b). The formation of an abnormal TNFR1 signaling complex in the presence of Phenhydan may help to explain the inhibitory effect of the drug on RIPK1-mediated cell death. With regard to the mechanism, it is possible that Phenhydan treatment prevents the autophosphorylation of RIPK1 (a major function of RIP1 kinase in TNF-induced cell death), which enables RIPK1 to recruit RIPK3 and form a functional necrosome [23].

Next, we tested whether Phenhydan interfered like etanercept (Enbrel ${ }^{\circ}$ ) and infliximab (Remicade ${ }^{\circ}$ ) with the binding of TNF to TNFR1. Nonetheless, an examination of the internalization kinetics of TNFR1 using labeled TNF $\alpha$ (Fig. 3c) and quantification of this internalization $30 \mathrm{~min}$ after ligand binding (Fig. 3d) excluded this possibility. Flow cytometry analysis of TNFR1 on the plasma membrane surface after labelling it with biotinylated TNF $\alpha / A l e x a$ Fluor ${ }^{\mathrm{TM}}$ 488-conjugated Streptavidin revealed only a slightly lower fluorescence intensity in cells pretreated with Phenhydan ${ }^{\circ}$ than in vehicle-treated cells (Fig. 3e, upper left). This outcome was in accordance with earlier data on TNF binding and internalization of the ligand/receptor complex, which were not markedly affected by Phenhydan .
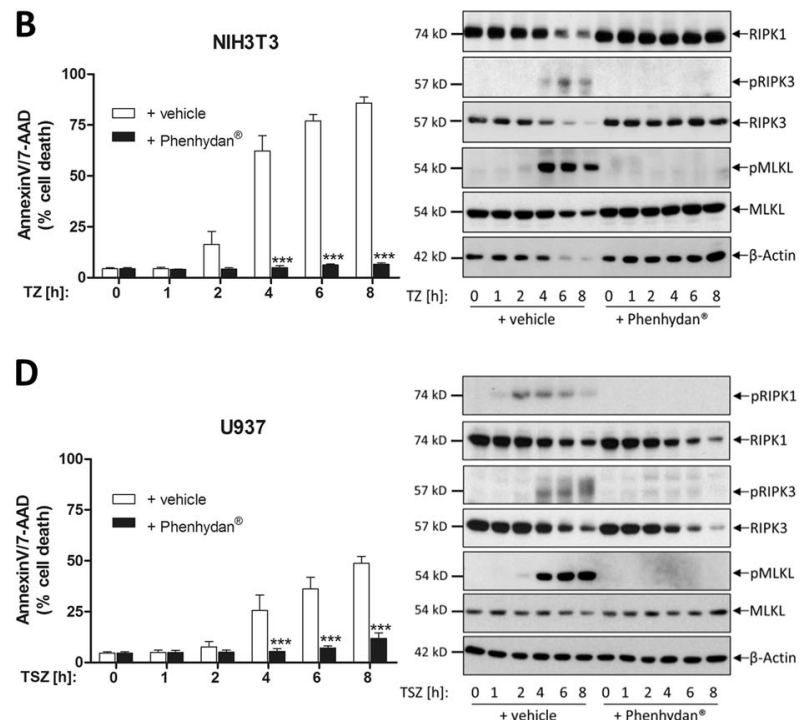

(Annexin V staining) as markers. Graphs show the mean \pm SEM; $n=4$ independent repeats. The whole expression level and activation status (phosphorylation) of the indicated necrosome member receptorinteracting serine/threonine protein kinase 1, receptor-interacting serine/threonine protein kinase 3, and Mixed lineage kinase domain-like protein after necroptosis in the absence or presence of Phenhydan were analyzed by western blotting, using the indicated specific antibodies. Notably, identical samples (time courses of different cell lines) to those analyzed by FACS were used in this approach. All blots were each re-developed with an antibody against $\beta$-actin as a loading control. One representative blot of four independent experiments is shown

To explain how Phenhydan ${ }^{\oplus}$ exerts its pharmacologic effects, at least in the context of TNF-mediated signaling, we explored whether this drug induces reorganization of the signaling machinery on the cell surface. The dynamic changes in plasma membranes can be resolved in real time by using lipophilic dyes that are readily incorporated into lipid structures. For our experiments, we used CellMask ${ }^{\mathrm{TM}}$ plasma membrane stains, which provide excellent and rapid plasma membrane staining in live cells without any celltype differences exhibited by Lectins. The dye does not have any biological function but shows strong fluorescence only when intercalated into the hydrophobic core of a biological membrane. The fluorescence spectrum presented in Fig. 3e (upper right) clearly indicates that the membrane structure of the cells, defined as changes in lipid order, is significantly affected in the presence of Phenhydan ${ }^{\star}$. To eliminate concerns that Phenhydan does not mediate a protective effect at the cellular level but only prevents interaction of CellMask ${ }^{\mathrm{TM}}$ with the cell surface, we monitored the fluorescence spectrum of CellMask ${ }^{\mathrm{TM}}$ before and after the addition of $1 \mathrm{mM}$ Phenhydan to U937 cells for up to $1 \mathrm{~h}$. Methyl- $\beta$-cyclodextrin $(\mathrm{M} \beta \mathrm{CD})$, which is a standardapproved cholesterol-depleting agent, served as an internal control. The data in Supplementary Fig. 3a clearly demonstrate that Phenhydan does not exert its effect 

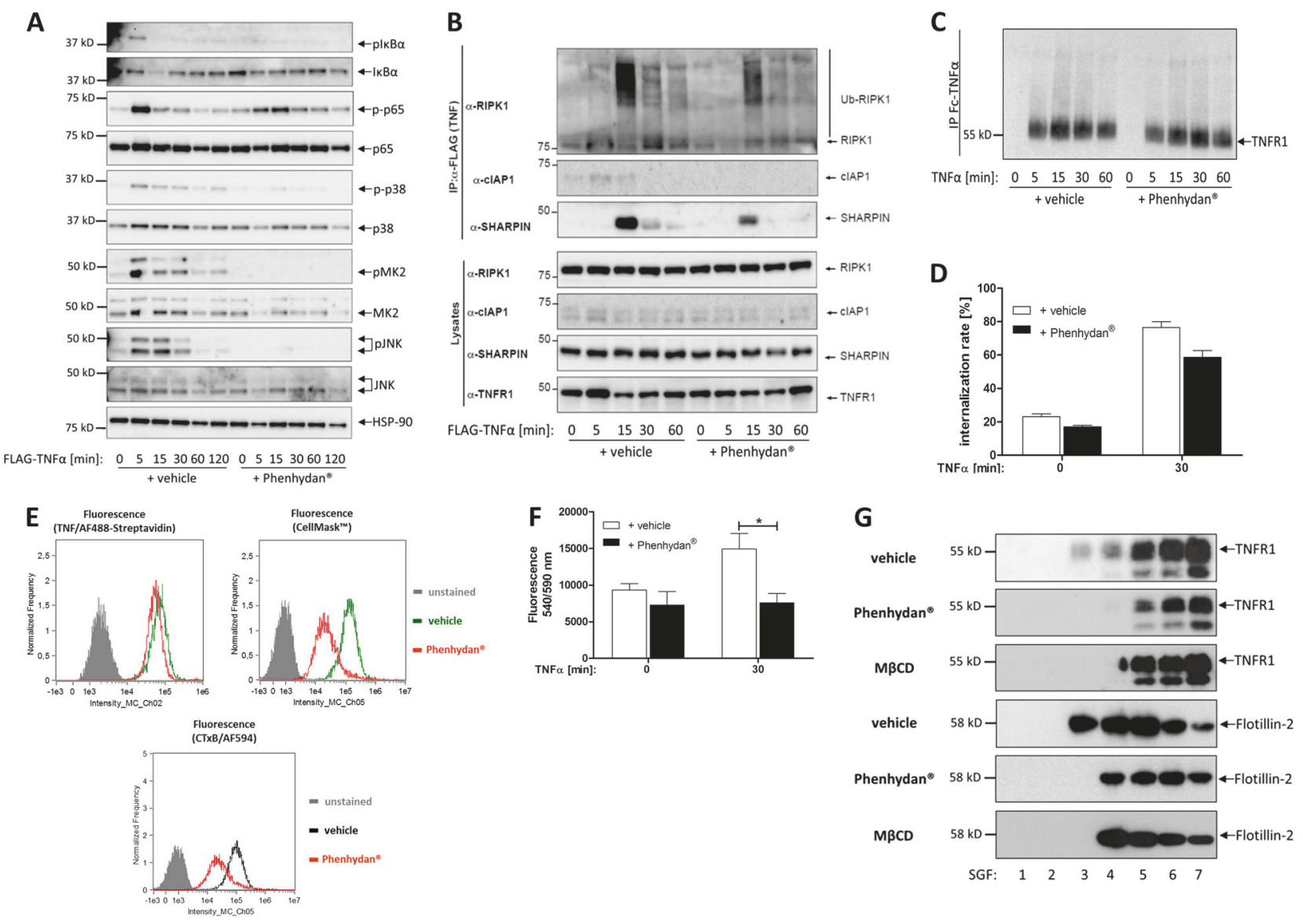

Fig. 3 Phenhydan prohibits canonical NF- $\mathrm{BB}$ signaling by influencing the membrane function of cells. Primary MEFs were treated in the absence or presence of $1 \mathrm{mM}$ Phenhydan ${ }^{\oplus}$ with $10 \mathrm{ng} / \mathrm{ml} \mathrm{TNF} \alpha$ for the indicated durations. Phenhydan ${ }^{\circ}$ was added $30 \mathrm{~min}$ before the addition of TNFo. a Western blotting analysis of the cell lysates using the indicated antibodies. b TNF $\alpha$-induced complex-I immunoprecipitation (IP) of primary MEFs treated in the absence or presence of $1 \mathrm{mM}$ Phenhydan with $1 \mu \mathrm{g} / \mathrm{ml}$ FLAG-tagged TNF $\alpha$ for the indicated durations, followed by FLAG IP and western blotting analysis using the indicated antibodies. c Deranged TNF receptor 1 (TNFR1) signaling in the presence of Phenhydan was ruled out by IP of TNFR1. Cells were treated in the absence or presence of $1 \mathrm{mM}$ Phenhydan with $100 \mathrm{ng} / \mathrm{ml} \mathrm{Fc}$-tagged TNF $\alpha$ for the indicated time points, followed by IP and western blotting analysis using a specific anti-TNFR1 antibody. d Quantification of TNFR1 internalization is described in the Materials and Methods section. Labelling of TNFR1 with $100 \mathrm{ng} / \mathrm{ml}$

merely by preventing the binding of the plasma membrane dye CellMask ${ }^{\mathrm{TM}}$ to the cell surface.

Our results so far are consistent with the notion that lipid rafts are essential for TNF $\alpha$-mediated activation of TNFR1 but dispensable for the activation of the NF- $\mathrm{KB}$ and MAPK pathways [24]. The plasma membrane is composed of discrete lipid microdomains in which membrane molecules are differentially partitioned [25]. Therefore, we used the fluorescein-labeled cholera toxin $\mathrm{B}$ subunit $(\mathrm{CTxB})$ to determine whether Phenhydan engagement affects the distribution of rafts, thereby leading to the alteration of cell death receptor signaling. The binding of $\mathrm{CTxB}$ to
biotinylated-TNF $\alpha$ and $5 \mu \mathrm{g} / \mathrm{ml}$ Alexa Fluor ${ }^{\mathrm{TM}}$ 488-conjugated Streptavidin was analyzed over time. The $30 \mathrm{~min}$ value \pm Phenhydan is shown representative for imaging flow cytometry. e CellMask ${ }^{\mathrm{TM}}$ Deep Red plasma membrane staining and subsequent cell analysis revealed the Phenhydan -mediated changes in the lipid bilayer properties, whereas staining in the presence of cholera toxin subunit B (CTxB) confirms that Phenhydan leads to the disruption of lipid rafts on the cell surface. f Acid sphingomyelinase (ASMase) activity assay indicates a distinct decreased activity of ASMase in the presence of Phenhydan . g U937 cells were incubated at $37^{\circ} \mathrm{C}$ for 30 min with 1 mM Phenhydan ${ }^{\circ}$ and $10 \mathrm{mM}$ methyl- $\beta$-cyclodextrin (M $\left.\beta C D\right)$, whereas control cells were vehicle-treated. Membrane lipid rafts and the detergent-soluble fraction were isolated by sucrose gradient centrifugation. From the top of the gradient, 1-ml sucrose gradient fractions were obtained and analyzed by western blotting for the indicated proteins

ganglioside GM1, which is enriched in lipid rafts, is considered as a marker of lipid rafts [26]. As shown in Fig. 3e, the fluorescence intensity of CTxB is markedly declined in the presence of Phenhydan ; this supports our hypothesis that the drug leads to increased disruption of lipid rafts. Accordingly, we noticed a distinct decrease in the activity of ASMase in the presence of Phenhydan ; this additionally indicates disruption of TNF-signaling downstream of TNFR1 (Fig. 3f).

It has been proposed that TNF receptor-mediated signaling relies on lipid-raft integrity [27]. Upon TNF binding, TNFR1 appears to translocate into these specialized 
membrane compartments, which are enriched in sphingolipids and cholesterol and serve as sorting platforms for signal transduction proteins. To substantiate our finding that lipid rafts and membrane composition are affected by Phenhydan ${ }^{\circ}$, we performed sucrose density gradient centrifugation to distinguish between lipid raft and non-lipid raft fractions. To this end, we isolated lipid rafts from whole cells (pretreated \pm Phenhydan ${ }^{\circ}$ ) and analyzed TNFR1 localization in the separate segregated fractions. Flotillin-2 was used as a lipid raft-associated marker [28]. As shown in Fig. 3g, in the absence of Phenhydan, TNFR1 was abundant in Fractions 3 and 4, representing the detergent-insoluble, glycolipid-enriched microdomains. This outcome is consistent with previous reports that TNFR1 can be recruited to lipid raft-containing fractions $[29,30]$. However, in the presence of Phenhydan, little if any TNFR1 was localized to the rafts (Fractions 3 and 4) and instead accumulated in the soluble fraction (Fractions 6 and 7). Treatment with methyl- $\beta$-cyclodextrin $(\mathrm{M} \beta \mathrm{CD})$, which is often used to disrupt lipid rafts [31], led to acute depletion of cholesterol from the plasma membrane; thus, the effect of M $\beta C D$ resembled that of Phenhydan . However, when it was used in an equimolar concentration to Phenhydan ${ }^{\bullet}$ (1 $\mathrm{mM}$ ), it did not exhibit an inhibitory effect on TNFmediated cell death (Supplementary Fig. 3b). Nevertheless, it should be mentioned that for effective disorganization of the lipid rafts, as shown before in Fig. 3g, M $\beta C D$ must be used in a 10-fold higher concentration $(10 \mathrm{mM})$. However, at such a high concentration, it is known [32] that M $\beta C D$ is toxic to a wide variety of cells already even with a short period of incubation $(<1 \mathrm{~h})$. This prevents a direct comparison of the mechanism of M $\beta C D$ and Phenhydan ${ }^{\circledR}$, with regard to their inhibitory effects in the course of ongoing $(>5 \mathrm{~h})$ necroptosis.

Of note, Phenhydan ${ }^{\circ}$ had no effect on erastin- or RSL3induced ferroptosis [22], suggesting that the drug does not inhibit any type of regulated cell death (Supplementary Fig. 4a). Furthermore, we found that IL-22-dependent activation of STAT3 in HT-29 cells and GM-CSFdependent STAT5 sensitivity in U937 cells were unaffected by the presence of Phenhydan (Supplementary Fig. 4b), indicating that Phenhydan does not generally block cytokine-mediated signal transduction.

Since Phenhydan suppresses TNFR1 signaling, we next tested whether it inhibits other pathogen recognition- or death receptor-initiated processes. To this end, we treated cells with FasL, TRAIL, and TLR agonists, which can induce apoptosis and necroptosis, depending on stimuli. As shown in Fig. 4a-e, we found that Phenhydan suppressed FasL-, TRAIL-, and TLR3-agonist induced cell death, which strongly suggests that Phenhydan interferes with death receptor signal transduction, most likely at an early stage such as their integration into lipid rafts. TLR3 is not a death receptor but is localized to and signals from acidified compartments of the endolysosomal pathway, and it mainly plays a role in the detection of nucleic acids of pathogens [33]. Nevertheless, inhibition or elimination of caspase-8 during stimulation of TLR3 results in RIP3 kinasedependent programmed necrosis that occurs through TIR domain-containing adapter-inducing interferon- $\beta$ (TRIF) [34]. TRIF, RIPK3, and MLKL promote cell death via a pathway that is analogous to the RIPK1-RIPK3-MLKL axis [7]. This mechanism may explain the protective effect of Phenhydan in TLR3-initiated cell death. Therefore, we assessed whether Phenhydan -mediated changes in the plasma membrane also affected the ability of MLKL to form pores, regardless the fact that the precise mechanism of this permeabilization has not yet been clarified so far [35-37]. To this end, we made use of a constitutively active form of MLKL (phosphomimetic S345D). Doxycyclineinducible expression of this MLKL mutant was reported to cause necroptosis independently of upstream signals [38]. Intriguingly, while induced expression of MLKL ${ }^{\text {S345D }}$ readily killed cells, in the presence of Phenhydan MLKL $^{\text {S345D }}$ was significantly less potent in killing cells (Fig. 4f). This suggests that Phenhydan -mediated changes of the lipid bilayer affect the ability of MLKL to form membrane apertures. At the membrane, it may either influence bilayer properties/structures or access target membrane proteins such as voltage-gated sodium channels to exert its pharmacologic action. The possibility that the mere presence of Phenhydan prevents or significantly reduces the doxycycline-induced expression of the constitutively active MLKL ${ }^{\text {S345D }}$, which may lead to an incorrect attribution of protection from necroptosis, was ruled out by direct comparison between MDFs isolated from MLKLko animals, MDFs from MLKL-ko animals in which wildtype MLKL was reconstituted, and the constitutively active MLKL mutant S345D. At $7 \mathrm{~h}$ after the addition of doxycycline, all inducible cells showed virtually identical protein expression of MLKL regardless of the presence or absence of Phenhydan (Supplementary Fig. 5).

The main purpose of our study was to identify an FDAapproved drug that, independent of its clinical application, possesses an inhibitory effect on pathophysiologic cell death, which might be suitable for emergency use. Since many inflammatory pathologies are driven by aberrant TNF-induced cell death, we tested whether Phenhydan could be used in vivo to suppress death receptor-induced cell death. To this end, we focused on clinically relevant in vivo models associated with pathophysiologic death receptor-induced cell death, such as renal IRI and immunemediated liver injury [39, 40]. Renal ischemia causes as well as frequently exacerbates already existing acute kidney disease (AKI) and chronic kidney disease [41]. For the mouse mode of IRI, animals underwent $47 \mathrm{~min}$ of bilateral 
A

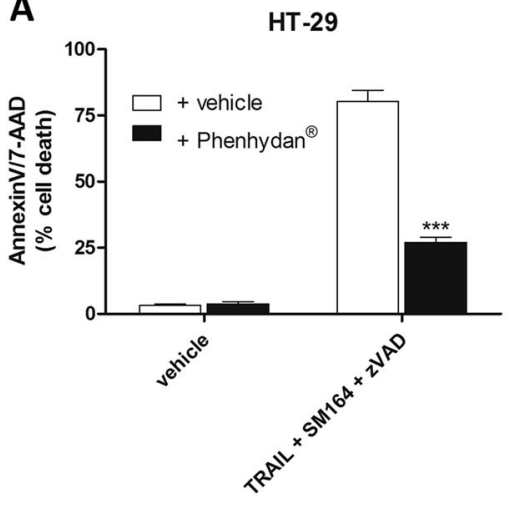

D

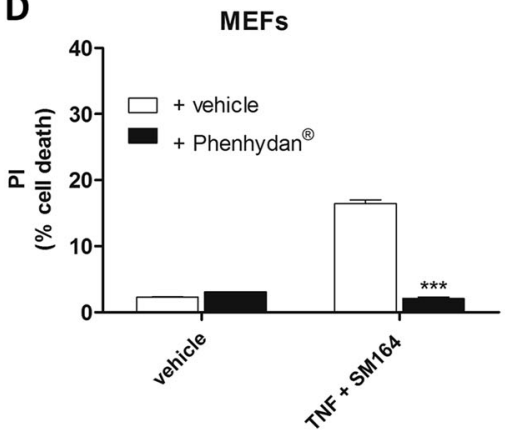

B

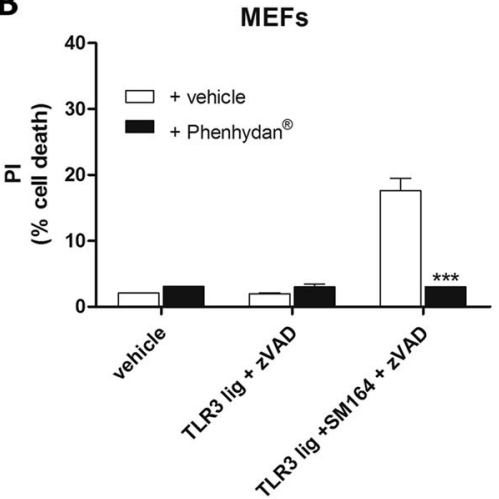

$\mathbf{E}$

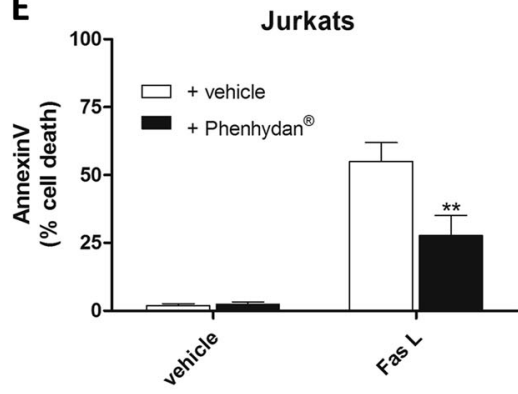

C

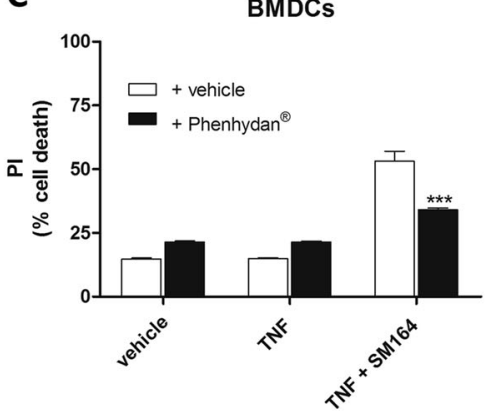

$\mathbf{F}$

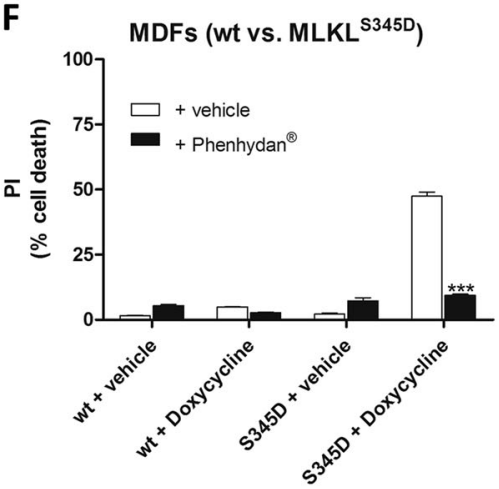

Fig. 4 The protective effect of Phenhydan against regulated cell death is not restricted to TNF-induced necroptosis. a HT-29 cells were stimulated at $37^{\circ} \mathrm{C}$ for $24 \mathrm{~h}$ with $200 \mathrm{ng} / \mathrm{ml}$ TRAIL $+1 \mu \mathrm{M}$ SMAC mimetic SM164 $+25 \mu \mathrm{M} z \mathrm{zAD}$ in the absence or presence of $1 \mathrm{mM}$ Phenhydan . b Similarly, primary MEFs were stimulated for $6 \mathrm{~h}$ at $37^{\circ}$ $\mathrm{C}$ with $10 \mu \mathrm{g} / \mathrm{ml}$ TLR3 ligand $+1 \mu \mathrm{M}$ SMAC mimetic SM164 +25 $\mu \mathrm{M}$ zVAD in the absence or presence of $1 \mathrm{mM}$ Phenhydan ${ }^{\circ}$. Both TRAIL and TLR3 ligand induced necroptotic cell death in a TNFindependent manner. c-e Phenhydan was also able to inhibit death receptor-mediated apoptosis. c Primary BMDCs and d MEFs were stimulated for 3 and $6 \mathrm{~h}$, respectively, at $37^{\circ} \mathrm{C}$ with $100 \mathrm{ng} / \mathrm{ml} \mathrm{TNF} \alpha$

renal pedicle clamping followed by $48 \mathrm{~h}$ of reperfusion. As described previously, such long-lasting ischemia is lethal in untreated wild-type mice $72 \mathrm{~h}$ after reperfusion [39]. In this setting, functional markers for the loss of kidney function (elevated serum concentrations of creatinine and urea) were significantly reduced $48 \mathrm{~h}$ after reperfusion in the presence of Phenhydan (Fig. 5b, c). This indicates the effectiveness and therapeutic potential of Phenhydan for the treatment of complex diseases driven by death receptor-induced cell death. Our conclusion is supported by representative periodic acid-Schiff-stained histomicrographs of the kidneys (Fig. 5a) and corresponding quantification of the injury based on the renal damage scores (Fig. 5d). The wellestablished TUNEL fluorescence assay, which is used to detect (Fig. 5f) and estimate the number of cells undergoing regulated necrotic death (Fig. 5e), confirmed at the cellular level the protective effect of Phenhydan in this clinically relevant in vivo model.
$+1 \mu \mathrm{M}$ SMAC mimetic SM164 in the absence or presence of $1 \mathrm{mM}$ Phenhydan . e Furthermore, human Jurkat cells were stimulated for $4 \mathrm{~h}$ at $37^{\circ} \mathrm{C}$ with $100 \mathrm{ng} / \mathrm{ml}$ FasL. f Wild-type or mutated (S345D Mixed lineage kinase domain-like protein) mouse dermal fibroblasts (MDFs) were induced at $37^{\circ} \mathrm{C}$ with $0.5 \mu \mathrm{g} / \mathrm{ml}$ doxycycline for $7 \mathrm{~h}$, before cells were harvested and permeabilized in Frackelton buffer. As indicated, $1 \mathrm{mM}$ Phenhydan ${ }^{\circ}$ was added $30 \mathrm{~min}$ before induction. The cell death that occurred in a-f was quantified by FACS analysis using the indicated markers. Graphs show the mean \pm SEM; $n=2-3$ independent experiments

To further corroborate the use of Phenhydan as a potential therapeutic agent for the treatment of diseases involving pathophysiologic cell death by death receptors, we use a murine model of inflammation-dependent hepatitis. Hepatitis was induced by intravenous injection of the Lectin ConA, which causes symptoms that resemble immune-mediated hepatitis in humans [42]. In this model MLKL seems to act as a central player because $M l k l$-knockout animals are protected from ConA injury and experimental hepatitis [40]. While treatment with ConA resulted in liver damage and hepatitis, co-treatment with Phenhydan greatly diminished plasma alanine aminotransferase (ALT) and aspartate aminotransferase (AST) concentrations, as well as considerably reduced lactate dehydrogenase (LDH) activity (Fig. 6b-d). Moreover, immunohistochemical analysis of these mice revealed significantly reduced liver tissue cell death following Phenhydan treatment (Fig. 6a). Just as in the IRI model, a TUNEL fluorescence assay was used to monitor (Fig. 6f) and evaluate 
A
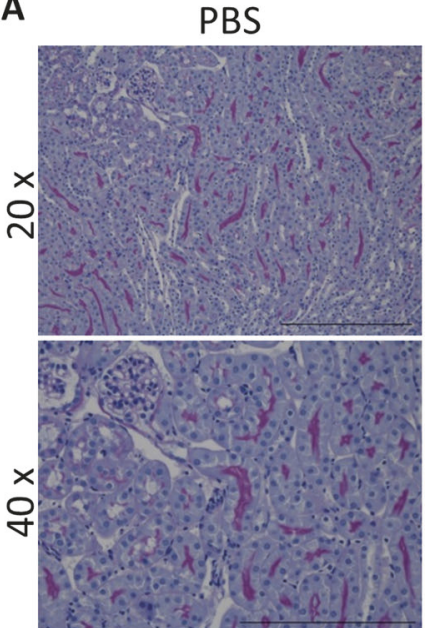

B

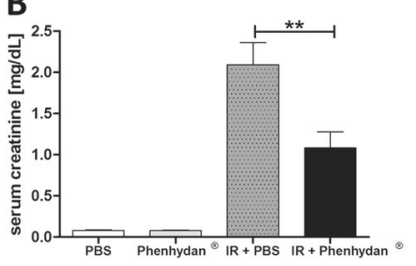

$\mathbf{F}$

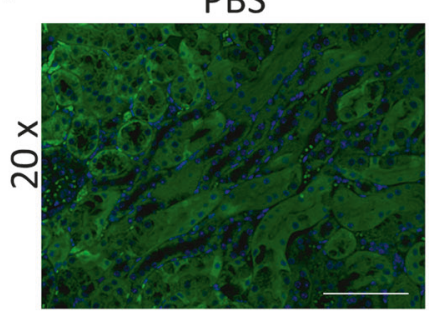

Phenhydan ${ }^{\circledR}$
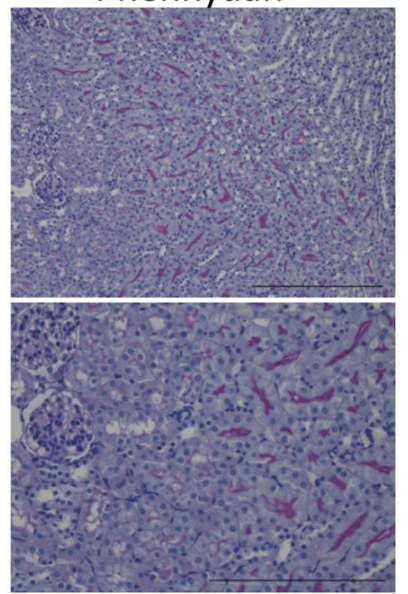

C

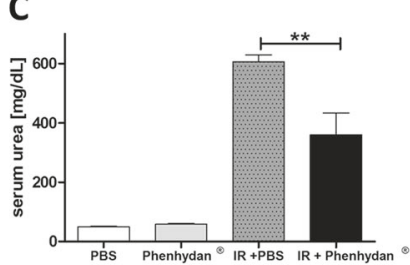

Phenhydan ${ }^{\circledR}$

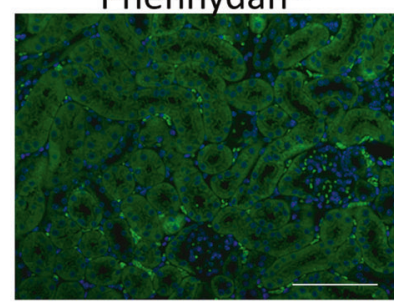

Fig. 5 Phenhydan provides protection from ischemia-reperfusion damage. The significant therapeutic effect of Phenhydan was evident under exceptionally severe test conditions. For establishing a renal ischemia-reperfusion injury model, all the mice ( $n=8$ per group) underwent $47 \mathrm{~min}$ of bilateral renal pedicle clamping followed by $48 \mathrm{~h}$ of reperfusion. In the verum group, Phenhydan was added at a final concentration of $1 \mathrm{mM}$ to the drinking water (renewed every day) 7 days before the onset of ischemia and until the end of the reperfusion phase. a Periodic acid-Schiff-stained histomicrographs of the kidneys exhibited diminished total organ damage in the Phenhydan -treated

the number of cells undergoing regulated cell death (Fig. 6e) in this clinically relevant in vivo model. The extent of cell death induced by ConA, and especially the impressive protective effect of Phenhydan, is illustrated in Fig. 6e, f.

\section{Discussion}

Receptor-interacting serine/threonine protein kinase 1 (RIPK1) has been shown to be a critical driver of various pathways downstream of the death receptors TNFR1, FasL, and TRAIL, as well as toll-like receptors. Hence, blocking these pathways has the potential to result in a broad
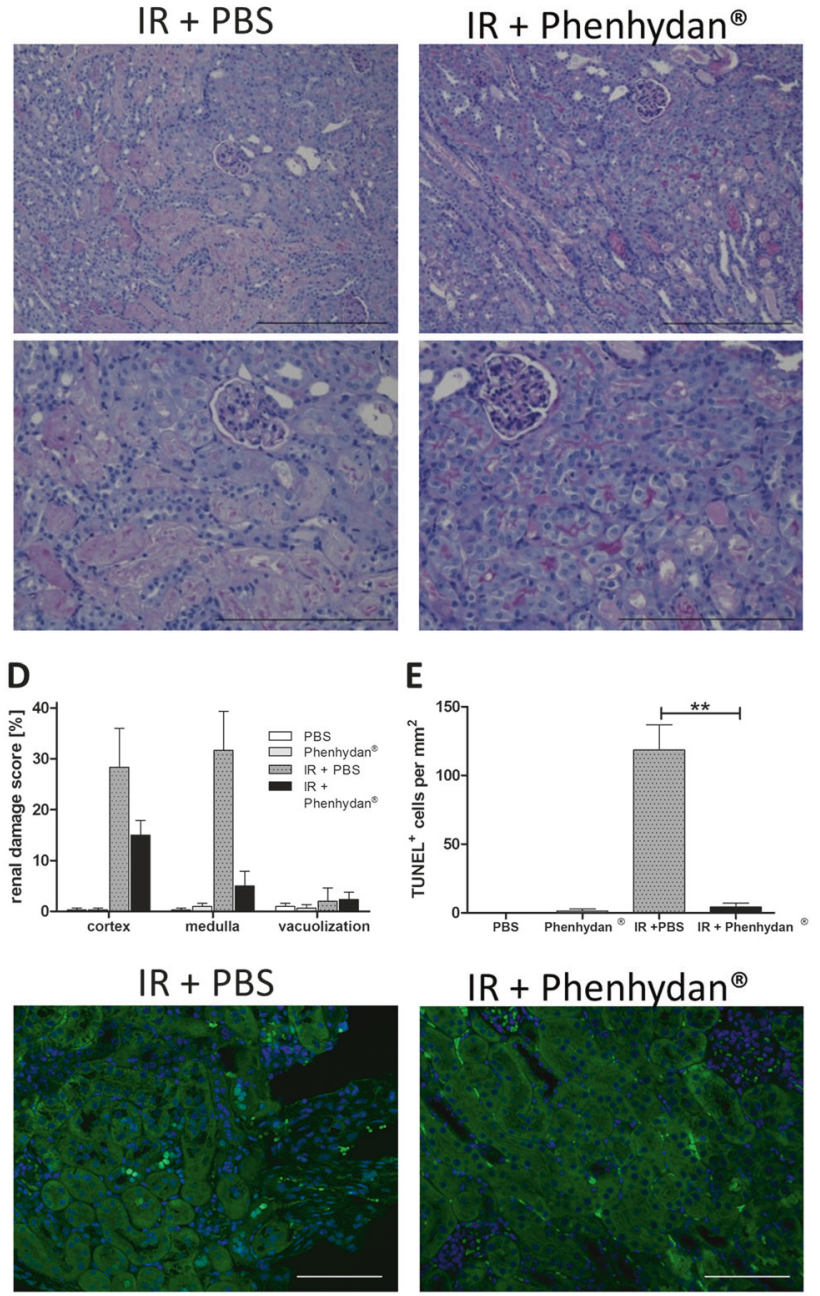

mice compared with the vehicle-treated animals (scale bar $=300 \mu \mathrm{m}$ $[20 \times]$ and $200 \mu \mathrm{m}[40 \times]$, respectively). Accordingly, we observed that the vehicle-treated mice had significantly lower plasma levels of serum creatinine (b) and urea (c) than the Phenhydan -treated animals. d The protective effect of Phenhydan in this model was confirmed by quantification of the renal damage. e, $\mathbf{f}$ To illustrate the protective effect of Phenhydan at the cellular level, a TUNEL fluorescence assay was performed to detect (f) and quantify (e) cells undergoing regulated necrotic death (in green) in this clinically relevant in vivo model. DAPI was used for nuclear counterstaining (blue). Scale bar $=100 \mu \mathrm{M}$

therapeutic benefit for multiple diseases such as ischemiareperfusion injury, myocardial infarction, sepsis, and multiple sclerosis. Since TNF $\alpha$ is involved in mediating a plethora of human diseases, the inhibition of RIPK1 may benefit patients beyond the indications that are currently being tested. Above all, GlaxoSmithKline (GSK) and Denali Therapeutics have identified and optimized a set of RIPK1 inhibitors and several human clinical trials as treatments of inflammatory and neurodegenerative diseases from ulcerative colitis and rheumatoid arthritis to amyotrophic lateral sclerosis (ALS) and Alzheimer's disease (AD) have been initiated [43]. Nevertheless, none of these exciting compounds reached Phase-III clinical studies today 
A
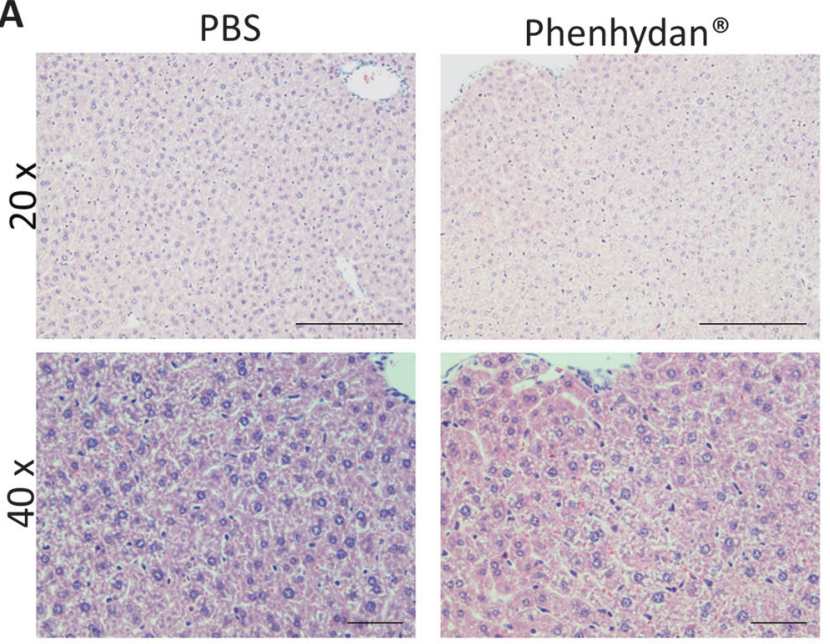

B

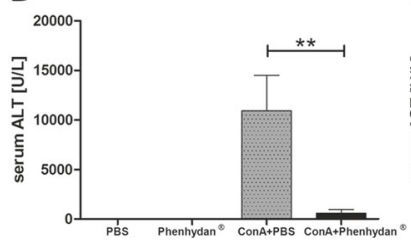

$\mathbf{F}$

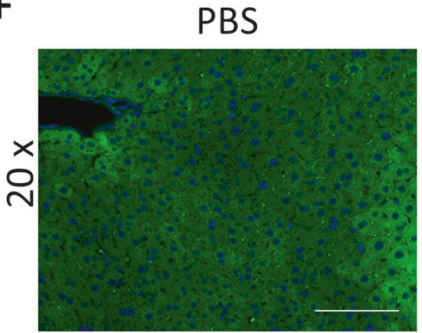

c
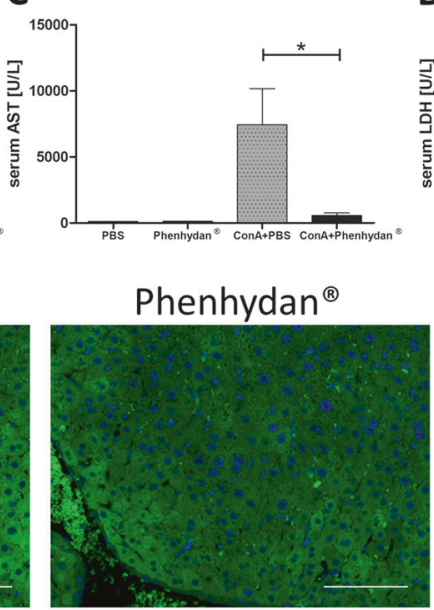

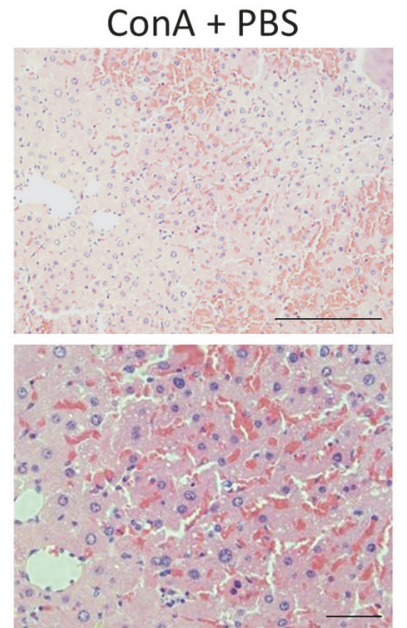

ConA + Phenhydan ${ }^{\circledR}$
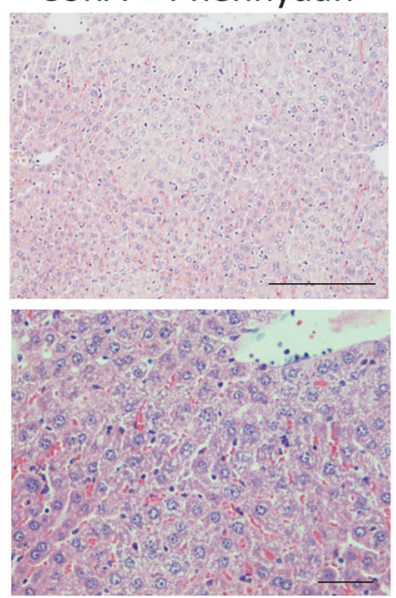

D

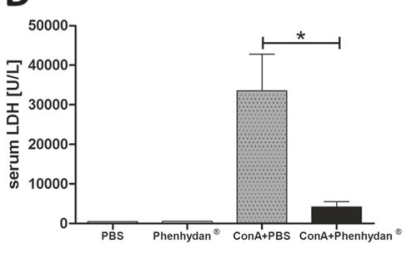

E
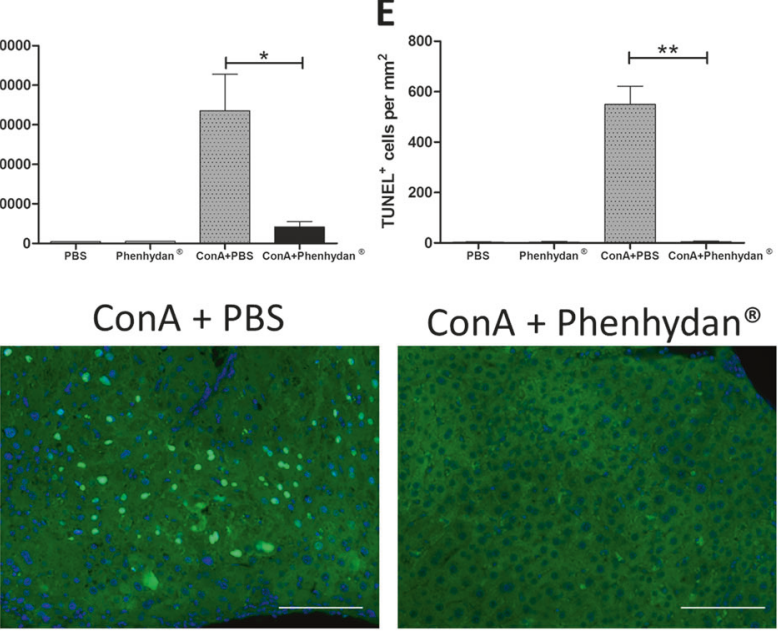

ConA + Phenhydan ${ }^{\circledR}$

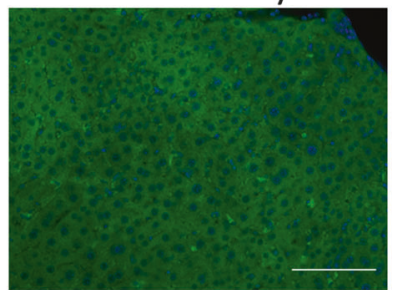

Fig. 6 Phenhydan ${ }^{\bullet}$ has protective effects in an in vivo model of inflammation-dependent hepatitis. The beneficial effects of Phenhydan in diseases involving pathophysiologic necroptosis were confirmed in a murine model of inflammation-dependent hepatitis. Mice ( $n=10$ per group) were subjected to ConA or saline treatment as described in the Materials and Methods section and analyzed $7 \mathrm{~h}$ after administration. a Immunohistochemical analysis revealed distinctly reduced liver tissue necrosis and hepatocyte death in the Phenhydan treated mice compared with the vehicle-treated animals (scale bar $=$
$200 \mu \mathrm{m}[20 \times]$ and $50 \mu \mathrm{m}[40 \times]$, respectively). b-d Compared with the control group, the Phenhydan -treated animals had considerably reduced plasma alanine aminotransferase (ALT) and aspartate aminotransferase (AST) concentrations as well as considerably reduced lactate dehydrogenase (LDH) activity. e, f To visualize the protective effect of Phenhydan ${ }^{\circledR}$, we performed a TUNEL fluorescence assay to detect (f) and quantify (e) cells undergoing regulated necrotic death (in green) in this model of liver injury. DAPI was used for nuclear counterstaining (blue). Scale bar $=100 \mu \mathrm{M}$ and accordingly, no pharmacologic inhibitor of RIPK1mediated cell death is currently in clinical use.

In the present study, we screened a selection of FDAapproved drugs with structures related to the RIPK1 inhibitor necrostatin-1 and identified the anti-epileptic drug Phenhydan in multiple cell types as a potent inhibitor of both pro-inflammatory NF-KB signaling and aberrant cell death. Furthermore, we were able to show that Phenhydan elicits these effects by influencing the membrane structure and function of cells. The initial formation of TNF/TNFR complexes is followed by secondary multimerization into supramolecular clusters, and it is known that efficient signal initiation requires the formation of larger ligand/receptor complexes [44]. It has been shown previously that besides TNF/TNFR complex, a considerable fraction of Fas is constitutively partitioned into cholesterol- and sphingolipidrich lipid rafts within the plasma membrane prior to ligation at a level that is not changed after Fas engagement. However, Fas ligation might trigger compositional changes in lipid rafts, suggesting that rafts represent the membrane site from which, upon engagement by its ligand, Fas initiates its signaling cascade [45]. Similarly, ligation of TRAILR1/2 localized to lipid rafts induces pro-cell death signaling, whereas TRAIL receptors that are not associated with lipid rafts mediate the activation of NF-KB [46]. Interestingly, it was reported that drugs, which induced the localization of 
TRAILRs to lipid rafts, resulted in enhanced TRAILmediated cell death [47]. According to our present data, Phenhydan $^{\oplus}$ has the opposite effect. This is consistent with the protective effect of the drug in the course of regulated cell death. Changes in lipid bilayer properties and lipid raft formation at an early stage alter membrane function, providing an indirect way for this drug to interfere with death receptor signal transduction, which goes beyond a simple modulation of necrosome formation/activation and merely inhibition of necroptotic cell death. The heterogeneity of the lipid composition of different cell lines is well known. Further, the number of physically distinct lipid raft domains in living cells is likely to be enormous [48]. Therefore, the clear separation of detergent-insoluble fractions from soluble ones is not often possible, and the degree of separation differs across cell lines. Since amphiphilic pharmacological compounds such as Phenhydan ${ }^{\circ}$ can be adsorbed at the bilayer interface and alter lipid bilayer properties [49], it is likely that Phenhydan ${ }^{\circledR}$ acts as a modulator of death receptor signaling by affecting the lipid bilayer properties of the plasma membrane, thus modifying the behavior of a range of membrane-bound proteins, including TNFR1.

Thus, changes in lipid bilayer properties, such as their ability to form lipid rafts or allow MLKL pore formation, could ultimately alter death receptor-mediated apoptosis and necroptosis. Phenhydan ${ }^{\circledR}$, therefore, might influence death receptor signaling in lipid rafts, and conditional redistribution of TNFR 1 in the plasma membrane is only one of the many possible mechanisms by which this drug regulates the efficiency of TNF signaling. At the molecular level, our statement is supported by the experiment shown in Fig. 3f. Determination of ASMase activity in the presence or absence of Phenhydan ${ }^{\circledR}$ was performed only in the presence of TNF but without the addition of the pan-caspase inhibitor zVAD. Upon binding of TNF to its corresponding receptor, internalization of this complex occurs immediately, and it was shown previously that this event causes rapid endosome formation [50]. The receptor-containing endosomes fuse with lysosomes, resulting in the formation of multivesicular bodies and bringing lysosomal ASMase into close contact with caspases, which cleave the $72 \mathrm{kDa}$ pro-form of ASMase into a $57 \mathrm{kDa}$ ASMase fragment and thereby activate the enzyme. Our data indicate that ASMase activation after TNF/TNFR1 internalization is significantly inhibited in the presence of Phenhydan ${ }^{\circ}$.

Moreover, by using two mouse models of death receptordriven pathology our data clearly demonstrate that Phenhydan ${ }^{\oplus}$ treatment suppresses death receptor-induced cell death also in vivo. On the one hand, we found that the anticonvulsive drug Phenhydan attenuated functional markers of acute kidney injury (AKI) and histological damage, indicating the effectiveness and therapeutic potential of Phenhydan ${ }^{\oplus}$ for the treatment of complex processes driven by death receptor-induced cell death like ischemia-reperfusion injury (IRI). In this context should be mentioned that AKI is associated with a high morbidity rate and is potentially lethal, and is therefore an emergency medical problem. Our limited understanding of the complex cell death mechanism in the process of AKI impedes the development of desirable therapeutics. To date, there is no effective therapy for AKI in clinical routine. Furthermore, we found that Phenhydan ${ }^{\circledR}$ ameliorates inflammationinduced programmed hepatocyte cell death, suggesting that clinical application of the drug in patients with steatosis and primary biliary cirrhosis is feasible with an inhibitor that is already available.

Given our findings, we suggest to repurpose Phenhydan ${ }^{\circledast}$ in settings where aberrant death receptor-mediated cell death might contribute to human inflammation driven pathologies, such as myocardial infarction, stroke, and organ/graft IRI. The well-defined safety profile of Phenhydan which is currently used in the clinic as anticonvulsant recommends it for Phase-III clinical trials in which the utility of the drug for the treatment of the aforementioned cell death-associated diseases should be verified. The application for a multicenter, randomized study using Phenhydan ${ }^{\circ}$, in which the objective is to reduce infarct volume during stent-retriever thrombectomy in acute ischemic stroke by inhibiting regulated cell death, has recently been submitted.

\section{Materials and methods}

\section{Cell lines}

L929, NIH3T3, HT-29, U937, and Jurkat cells were obtained from the American Type Culture Collection (Manassas, VA, USA). The isolation and immortalization of mouse dermal fibroblasts (MDFs) from the dermis of $M l k l$-knockout and congenic wild-type mice have been described previously [51]. The MDF cell lines, L929, NIH3T3, and HT-29 were cultured in DMEM (Gibco ; Thermo Fisher Scientific) supplemented with 10\% (vol/ vol) FCS (PAN-Biotech GmbH, Aidenbach, Germany), $100 \mathrm{U} / \mathrm{ml}$ penicillin, and $100 \mu \mathrm{g} / \mathrm{ml}$ streptomycin (Merck Millipore GmbH, Darmstadt, Germany). Jurkat cells were cultured in RPMI 1640 medium (Gibco ${ }^{\circ}$; Thermo Fisher Scientific) supplemented with 5\% (vol/vol) FCS, $100 \mathrm{U} /$ $\mathrm{ml}$ penicillin, and $100 \mu \mathrm{g} / \mathrm{ml}$ streptomycin. U937 cells were cultured in RPMI 1640 medium supplemented with $10 \%$ (vol/vol) FCS, 100U/ml penicillin, $100 \mu \mathrm{g} / \mathrm{ml}$ streptomycin, $1 \mathrm{mM}$ sodium pyruvate, and $0.25 \% \mathrm{D}-(+)$-glucose (Sigma-Aldrich Chemie GmbH, Taufkirchen, Germany). All cell lines were cultured in a humidified 5\% $\mathrm{CO}_{2}$ atmosphere. 


\section{Primary cells}

Primary MEFs were generated from E13.5 embryos. After removing the placenta, yolk sac, head, and dark red organs, the embryos were finely minced and digested for $20 \mathrm{~min}$ in $0.25 \%$ trypsin. A single-cell suspension was then obtained by pipetting the digested embryos up and down. To generate bone marrow-derived macrophages, bone marrow cells from the tibias and femurs of 2-month-old mice were seeded in non-coated Petri dishes and cultured for 6 days in DMEM supplemented with $10 \%$ (vol/vol) FCS and $20 \%$ (vol/vol) L929 mouse fibroblast-conditioned medium. Primary cells were cultured in a humidified $5 \% \quad \mathrm{CO}_{2}$ atmosphere.

\section{Reagents and antibodies}

Recombinant purified TNF $\alpha$, the Annexin V-FITC antibody, and the 7-amino-actinomycin $\mathrm{D}$ antibody were purchased from BioLegend (London, UK). Recombinant untagged TRAIL, TLR3 ligand, FLAG-tagged TNF $\alpha$, GMCSF, IL-22, anti-cIAP1, and anti-Heat shock protein 90 were obtained from Enzo Life Sciences GmbH (Lörrach, Germany). Fc-tagged human TNF $\alpha$ was manufactured by SinoBiological, the bivalent SMAC mimetic SM164 by AdooQ Biosciences, and RSL3 by Selleckchem (all purchased from Hölzel Diagnostika Handels $\mathrm{GmbH}$, Cologne, Germany). Biotinylated TNF $\alpha$ was purchased from Invitrogen (Carlsbad, CA, USA). Alexa Fluor ${ }^{\mathrm{TM}}$ 488conjugated Streptavidin, CellMask ${ }^{\mathrm{TM}}$, and cholera toxin subunit B (CTxB) Alexa Fluor ${ }^{\mathrm{TM}} 594$ conjugate were purchased from Thermo Fisher Scientific (Darmstadt, Germany). The pan-caspase inhibitor zVAD-fmk was purchased from Bachem (Weil am Rhein, Germany). ConA was obtained from Merck Millipore. $\alpha$-human Fas (clone 7C11) was purchased from Immunotech (Marseille, France). PR619, the monoclonal $\alpha$-FLAG M2 antibody, sucrose, $\mathrm{M} \beta \mathrm{CD}$, imidazole, hydantoin, and propidium iodide (PI) solution were purchased from Sigma-Aldrich Chemie GmbH. Drugs tested in this work were obtained from followed companies: Tavor (Pfizer Pharma GmbH, Berlin, Germany), Dormicum (Roche Pharma AG, Reinach, Switzerland), Brevimytal ${ }^{\circ}$ (Hikma Pharma GmbH, Martinsried, Germany), Luminal ${ }^{\circ}$ and Phenhydan ${ }^{\circ}$ (both from Desitin Arzneimittel GmbH, Hamburg, Germany). The anti-ubiquitin antibody was obtained from Dako (Biozol Diagnostica Vertrieb GmbH, Eching, Germany) and the $\alpha$-SHARPIN antibody was purchased from Proteintech (Manchester, UK). Erastin, GSK' 872 and the anti-MLKL antibody (clone 3H1) were obtained from Calbiochem (Merck Millipore). The murine MLKL inhibitor GW806742X was purchased from Biomol (Hamburg, Germany). Ferrostatin-1 was purchased from Xcess
Biosciences Inc. (San Diego, CA, USA). The anti-human as well as the anti-mouse monoclonal phospho-MLKL antibodies, the anti-cholera toxin subunit B (CTxB) antibody, and the anti-TNFR1 antibody were obtained from Abcam (Berlin, Germany). The anti-RIPK3 antibody (human- and mouse-specific) was obtained from ProSci Incorporated (Hölzel Diagnostika Handels GmbH). Anti-RIPK1 (humanand mouse-specific), anti-human and anti-murine phosphoRIPK1, anti-murine phospho-RIPK3, anti-JNK, anti-phospho-JNK, anti-IкB $\alpha$, anti-phospho-IкB $\alpha$, anti-MK2, antiphospho-MK2, anti-p38, anti-phospho-p38, anti-p65, antiphospho-p65, anti-phospho-STAT3/5, anti-Flotillin-2, and the $\beta$-actin antibody were purchased from Cell Signaling Technology Europe BV (Frankfurt, Germany).

\section{Assessment of cell death in vitro}

Phosphatidylserine exposure to the outer cell membrane of apoptotic cells or inner plasma membrane of necrotic cells and incorporation of 7-amino-actinomycin D into necrotic cells was quantified by FACS analysis. Stainings were performed according to the manufacturer's instructions (BioLegend). Fluorescence was analyzed using an FC-500 flow cytometer (Beckman Coulter $\mathrm{GmbH}$, Krefeld, Germany).

\section{Analysis of cell death by western blotting}

For immunoblotting, cells were lysed in ice-cold $10 \mathrm{mM}$ Tris- $\mathrm{HCl}$ (pH 7.5), $50 \mathrm{mM} \mathrm{NaCl}, 1 \%$ Triton X-100, $30 \mathrm{mM}$ $\mathrm{Na}_{4} \mathrm{P}_{2} \mathrm{O}_{7}, 50 \mathrm{mM} \mathrm{NaF}, 100 \mu \mathrm{M} \mathrm{Na} \mathrm{VO}_{4}, 2 \mu \mathrm{M} \mathrm{ZnCl}$, and $1 \mathrm{mM} \mathrm{C} \mathrm{C}_{7} \mathrm{H}_{7} \mathrm{FO}_{2} \mathrm{~S}$ (PMSF) (modified Frackelton buffer). Insoluble material was removed by centrifugation $\left(14,000 \times g, 10 \mathrm{~min}, 4^{\circ} \mathrm{C}\right)$ and protein concentration was determined using a commercial Bradford assay kit according to the manufacturer's instructions (Bio-Rad Laboratories $\mathrm{GmbH}$, Munich, Germany). Equal amounts of protein (20 $\mu \mathrm{g}$ per lane) were resolved by reducing SDS/PAGE and transferred to a polyvinylidene fluoride (PVDF) membrane (GE Healthcare Life Sciences, Freiburg, Germany). Western blots were performed using the specific primary antibodies mentioned above and corresponding secondary horseradish peroxidase-linked polyclonal antibodies obtained from Abcam (Berlin, Germany). Immune complexes were visualized by enhanced chemiluminescence (ECL).

\section{Mice}

Mice used in this study were of the C57BL/6 background and were purchased from Janvier Labs (Saint Berthevin Cedex, France). All mice were carefully matched for age, sex, and weight. For our analyses, the animals used were 
male mice at an age of 8 weeks. All mice were kept on a standard diet and a 12-h day-night rhythm. All in vivo experiments were performed according to the Protection of Animals Act with the approval of German and French local authorities.

\section{Ischemia-reperfusion injury}

Induction of murine kidney IRI was performed via a midline abdominal incision and bilateral renal pedicle clamping for $47 \mathrm{~min}$ using microaneurysm clamps (Aesculap, Inc., Center Valley, PA USA). Throughout the surgical procedure, the body temperature of the mice was maintained at between $36^{\circ} \mathrm{C}$ and $37^{\circ} \mathrm{C}$ by continuous monitoring using a temperature-controlled self-regulated heating system (Fine Science Tools GmbH, Heidelberg, Germany). After removal of the clamps, reperfusion of the kidneys was confirmed visually. The abdomen was closed in two layers using standard 6-0 sutures. To maintain fluid balance, all of the mice were supplemented with $1 \mathrm{ml}$ of prewarmed PBS administered intraperitoneally directly after surgery. The mice were sacrificed $48 \mathrm{~h}$ after reperfusion. Serum creatinine and urea values were measured in the Central laboratory of the University Hospital Schleswig-Holstein, Kiel (Germany). IRI experiments were performed in a double-blinded manner. Where indicated, Phenhydan ${ }^{\oplus}$ was added at a final concentration of $1 \mathrm{mM}$ to the drinking water (renewed every day) of the mice 7 days before the onset of ischemia and until the end of the reperfusion phase.

\section{In vivo model of liver injury}

C57BL/6 mice were subjected to ConA or saline treatment and sacrificed $7 \mathrm{~h}$ later. ConA was administered intravenously at a concentration of $15 \mathrm{mg} / \mathrm{kg}$ body weight. Where indicated, a singular injection of Phenhydan was administered intraperitoneally at a concentration of $34 \mathrm{mg} / \mathrm{kg}$ body weight (total volume per mouse was $200 \mu \mathrm{l}) 30 \mathrm{~min}$ before ConA administration. Appropriate amount of PBS ( $200 \mu \mathrm{l}$ per mouse) was applied as vehicle control. The plasma concentrations of alanine aminotransferase, aspartate aminotransferase, and lactate dehydrogenase were measured in the Central laboratory of the Universite Pierre et Marie Curie, Paris (France) as well as in the Central laboratory of the University Hospital Schleswig-Holstein, Kiel (Germany).

\section{Histologic, immunohistochemical, and morphologic assessments}

Kidney and liver biopsies were fixed in $4 \%$ neutral-buffered formaldehyde and embedded in paraffin. The $3-\mu \mathrm{m}$ sections produced were dewaxed, rehydrated, and subjected to periodic acid-Schiff staining (kidney) and haematoxylin and eosin (liver) according to routine protocols. Stains were evaluated blinded by an experienced pathologist. Sections were evaluated using an U-DO3 microscope (Olympus Corp., Tokyo, Japan). Representative photomicrographs were taken using a Zeiss system (an Axioplan microscope with an MRT digital camera and Axiovision Software; Carl Zeiss AG, Oberkochen, Germany).

To analyze cell death of the tissue sections, the TdTmediated dUTP nick end labeling (TUNEL) assay was performed using the fluorescence detection kit according to the manufacturer's instructions (Promega, Mannheim, Germany). Briefly, tissue sections were dewaxed, rehydrated, fixed in $4 \%$ paraformaldehyde and permeabilized with Proteinase K for $10 \mathrm{~min}$ at RT. Following this, the sections were equilibrated with the provided buffer for 10 min and labeled with the TdT reaction mix for $60 \mathrm{~min}$ at $37^{\circ} \mathrm{C}$ in a humidified dark environment. To stop the labeling reactions, sections were incubated with the provided stopping buffer for $15 \mathrm{~min}$ at $\mathrm{RT}$ in the dark. The sections were then washed with PBS for $5 \mathrm{~min}$. Finally, the sections were mounted with fluorescence-mounting media (Dako, Glostrup, Denmark) containing 4',6-Diamidin-2-phenylindol (DAPI) for cell nuclei counterstaining. Fluorescence micrographs were taken using Zeiss Axio Imager Z1 fluorescence microscope (Carl Zeiss AG, Oberkochen, Germany) at magnifications of $20 \times$ and $40 \times$ magnification using a standard fluorescein filter set to view the green fluorescence at $520 \mathrm{~nm}$, and blue fluorescence of DAPI at $380 \mathrm{~nm}$. Quantification of TUNEL-positive cells was performed manually by two blinded observers and reproduced in triplicate by each of them.

\section{Complex-I purification}

MEFs were seeded in $15-\mathrm{cm}$ dishes and treated as indicated with $3 x$ FLAG-TNF $\alpha(5 \mathrm{mg} / \mathrm{ml})$. The medium was removed and the plates were washed with ice-cold PBS. Then, the plates were frozen at $-80^{\circ} \mathrm{C}$. The plates were later thawed on ice and the cells were lysed in $1 \%$ Triton X-100 lysis buffer $(30 \mathrm{mM}$ Tris- $\mathrm{HCl}$ [pH 7.4], $120 \mathrm{mM} \mathrm{NaCl}, 2 \mathrm{mM}$ EDTA, $2 \mathrm{mM} \mathrm{KCl}, 10 \%$ glycerol, and $1 \%$ Triton X-100) plus protease inhibitors and $10 \mathrm{mM}$ PR619 (inhibitor of ubiquitin isopeptidases). The cell lysates were rotated at $4^{\circ}$ $\mathrm{C}$ for $20 \mathrm{~min}$ and then clarified at $4{ }^{\circ} \mathrm{C}$ for $30 \mathrm{~min}$ at $14,000 \times g$. The proteins were immunoprecipitated using 20 $\mathrm{ml}$ of $\alpha$-FLAG M2 beads with rotation overnight at $4{ }^{\circ} \mathrm{C}$. For the $0 \mathrm{~min}$ sample, $5 \mathrm{mg} / \mathrm{ml}$ of FLAG-TNF $\alpha$ was added post-lysis. The beads were washed four times in lysis buffer and the samples were eluted by boiling in $60 \mu \mathrm{l}$ of 1x SDS loading dye. 


\section{Immunoprecipitation assay}

For TNFR1 immunoprecipitation (IP), $1 \times 10^{7}$ U937 cells were preincubated for $30 \mathrm{~min}$ with $1 \mathrm{mM}$ Phenhydan ${ }^{\circ}$ or the appropriate amount of DMSO as a vehicle control. Next, the cells were treated for $0,5,15,30$, and $60 \mathrm{~min}$, respectively, at $37^{\circ} \mathrm{C}$ with $100 \mathrm{ng} / \mathrm{ml}$ FLAG-tagged or Fc-tagged human $\mathrm{TNF} \alpha$. The cells were collected into tubes pre-cooled on ice containing ice-cold PBS, centrifuged at 1,500 RPM, washed with ice-cold PBS, lysed in IP buffer $(50 \mathrm{mM}$ Tris- $\mathrm{HCl}[\mathrm{pH}$ 7.4], $150 \mathrm{mM} \mathrm{NaCl}, 1 \% \mathrm{NP}-40,0.25 \%$, Na-deoxycholate, $1 \%$ Triton X-100, $1 \mathrm{mM}$ EDTA, $100 \mu \mathrm{M} \mathrm{Na} \mathrm{VO}_{4}$, and $1 \mathrm{mM}$ $\mathrm{C}_{7} \mathrm{H}_{7} \mathrm{FO}_{2} \mathrm{~S}$ (PMSF) and kept on ice for $20 \mathrm{~min}$. For the $0 \mathrm{~min}$ sample, $100 \mathrm{ng} / \mathrm{ml} \mathrm{TNF} \alpha$ was added post-lysis. The cell lysates were clarified at $4{ }^{\circ} \mathrm{C}$ for $10 \mathrm{~min}$ at $14,000 \times g$. For IP, the lysates were incubated with $50 \mu \mathrm{l}$ of $\mu \mathrm{MACS}^{\mathrm{TM}}$ Protein $\mathrm{G}$ MicroBeads (Miltenyi Biotec GmbH, Bergisch Gladbach, Germany) and rotated at $4{ }^{\circ} \mathrm{C}$ for $2 \mathrm{~h}$. The lysates were applied to $\mu$ Columns (Miltenyi Biotec $\mathrm{GmbH}$ ) pre-wetted with IP buffer, washed with IP buffer, and eluted with $40 \mu$ of pre-warmed $95^{\circ} \mathrm{C}$ SDS loading buffer. Of each sample (eluate), $20 \mu \mathrm{l}$ was loaded for western blotting analysis.

\section{Acid Sphingomyelinase activity}

Acid Sphingomyelinase (ASMase) activity was determined using an Acidic Sphingomyelinase Assay Kit from Abcam (Berlin, Germany) following the manufactures instructions. As indicated, U937 were pretreated at $37{ }^{\circ} \mathrm{C}$ for $30 \mathrm{~min}$ with vehicle or $1 \mathrm{mM}$ Phenhydan followed by a stimulation with $100 \mathrm{ng} / \mathrm{ml}$ human $\mathrm{TNF} \alpha$ for $30 \mathrm{~min}$ at $37^{\circ} \mathrm{C}$. Then, cells were lysed in ice-cold $10 \mathrm{mM}$ Tris- $\mathrm{HCl}(\mathrm{pH} 7.5), 50 \mathrm{mM}$ $\mathrm{NaCl}, 1 \%$ Triton $\mathrm{X}-100,30 \mathrm{mM} \mathrm{Na} \mathrm{P}_{2} \mathrm{O}_{7}, 50 \mathrm{mM} \mathrm{NaF}$, $100 \mu \mathrm{M} \quad \mathrm{Na}_{3} \mathrm{VO}_{4}, 2 \mu \mathrm{M} \quad \mathrm{ZnCl}_{2}$, and $1 \mathrm{mM} \quad \mathrm{C}_{7} \mathrm{H}_{7} \mathrm{FO}_{2} \mathrm{~S}$ (PMSF) (modified Frackelton buffer). Cellular debris was removed by centrifugation $\left(14,000 \times g, 10 \mathrm{~min}, 4{ }^{\circ} \mathrm{C}\right)$. Lysate of $1 \times 10^{6}$ cells each were used to determine ASMase activity by measuring of the fluorescence $\left(\lambda_{\mathrm{ex}} 540 \mathrm{~nm}\right.$ and $\lambda_{\text {em }} 590 \mathrm{~nm}$ ) in the Infinite 200 PRO plate reader from Tecan (Männedorf, Switzerland).

\section{Sucrose gradient}

We incubated $1 \times 10^{8}$ U937 cells in $3 \mathrm{ml}$ of RPMI 1640 medium at $37^{\circ} \mathrm{C}$ for $30 \mathrm{~min}$ with $1 \mathrm{mM}$ Phenhydan ${ }^{\circ}, 10$ $\mathrm{mM} \mathrm{M} \beta \mathrm{CD}$, or vehicle alone (control). Subsequently, the cells were collected by centrifugation at 1,500 RPM, washed with ice-cold PBS, and incubated with $2 \mathrm{ml}$ TXbuffer (25 mM Tris [pH 6.5], $150 \mathrm{mM} \mathrm{NaCl,} 5 \mathrm{mM}$ EDTA, $1 \%$ Triton X-100 including protease inhibitor cocktail) at 4 ${ }^{\circ} \mathrm{C}$ for $3 \mathrm{~h}$ followed by sonication for $15 \mathrm{sec}$. The cell lysate was mixed with an equal volume of $95 \%$ sucrose $(w / v)$ in Tbuffer (25 mM Tris [pH 6.5], $150 \mathrm{mM} \mathrm{NaCl}, 5 \mathrm{mM}$ EDTA) and placed into ultracentrifugation tubes. The cell lysate mixtures were overlaid sequentially with $4 \mathrm{ml}$ of $35 \%$ (w/v) sucrose and $4 \mathrm{ml}$ of $5 \%(\mathrm{w} / \mathrm{v})$ sucrose, each in T-buffer, and centrifuged using an SW $32 \mathrm{Ti}$ rotor (Beckman Coulter $\mathrm{GmbH}$ ) for $19 \mathrm{~h}$ at $143,000 \times g$. We collected $1 \mathrm{ml}$ of the fractions (numbered according to Fig. $3 \mathrm{~g}$ from 1 to 7 ) from the top of the gradient and used them for protein analysis via western blotting.

\section{ImageStream analysis}

For quantification of TNFR1 internalization by imaging flow cytometry, cells were incubated for $15 \mathrm{~min}$ at room temperature with vehicle or $1 \mathrm{mM}$ Phenhydan, respectively, followed by sedimentation and cooling on ice for 15 min. Labeling of TNFR 1 with $100 \mathrm{ng} / \mathrm{ml}$ biotinylated TNF $\alpha$ and $5 \mu \mathrm{g} / \mathrm{ml}$ Alexa Fluor ${ }^{\mathrm{TM}}$ 488-conjugated Streptavidin was performed on ice for $20 \mathrm{~min}$. To facilitate receptor internalization, the temperature was raised to $37^{\circ} \mathrm{C}$ with pre-warmed medium for $30 \mathrm{~min}$. Thereafter, the cells were fixed in $2 \%$ paraformaldehyde/PBS for $20 \mathrm{~min}$ without permeabilization. CellMask ${ }^{\mathrm{TM}}$ Deep Red plasma membrane stain (1:10,000 dilution of the stain) was added for the final 5 min. The cells were washed twice with PBS and the cell pellet was resuspended in $20 \mu \mathrm{l}$ of PBS.

The ImageStream Mark II was used for cell analysis. At least 5000 images were acquired, detecting the internalization probes biotinylated TNFo/Alexa Fluor ${ }^{\mathrm{TM}}$ 488conjugated Streptavidin (excitation: $488 \mathrm{~nm}$ ) on Channel 2 and the cell surface label CellMask ${ }^{\mathrm{TM}}$ (excitation: $642 \mathrm{~nm}$ ) on Channel 5. We applied the internalization wizard of the software Amnis IDEAS (version 6.0.154.0) according to the instruction manual, to determine the TNF/TNFR1 internalization rate in vehicle-treated versus Phenhydan -treated U937 cells. For monitoring time-dependent CellMask ${ }^{\mathrm{TM}}$ fluorescence in the presence of Phenhydan ${ }^{\circledR} 3 \times 10^{4}$ U937 per value were resuspended in $300 \mu \mathrm{PBS}$ and pretreated with $1 \mathrm{mM}$ Phenhydan or $10 \mathrm{mM}$ methyl- $\beta$-cyclodextrin $(\mathrm{M} \beta \mathrm{CD})$ for $30 \mathrm{~min}$, representing the time frame from -30 to 0 min. Following this, CellMask ${ }^{\mathrm{TM}}(1: 10,000$ dilution of the stain) was added in each well ( 0 up to $30 \mathrm{~min}$ ). Conversely, cells were first incubated for $30 \mathrm{~min}$ with Cell$\operatorname{Mask}^{\mathrm{TM}}$ (-30 to $0 \mathrm{~min}$ ) and then mixed with $1 \mathrm{mM}$ Phenhydan (0 to $30 \mathrm{~min}$ ). The measurements were performed at $37{ }^{\circ} \mathrm{C}$ in a black 96-well plate, and fluorescence $\left(\lambda_{\text {ex }} 642 \mathrm{~nm}\right.$ and $\lambda_{\text {em }} 666 \mathrm{~nm}$ ) was measured with the Infinite 200 PRO plate reader from Tecan. Samples were measured in triplicate every $15 \mathrm{~min}$ over a period of $1 \mathrm{~h}$.

The fluorescence intensity of cholera toxin subunit B (CTxB) conjugated with Alexa Fluor ${ }^{\mathrm{TM}} 594$ was also measured via flow cytometry using ImageStream Mark II (excitation: $590 \mathrm{~nm}$ on Channel 5). As indicated, U937 cells were pretreated at $37^{\circ} \mathrm{C}$ for $30 \mathrm{~min}$ with vehicle or $1 \mathrm{mM}$ 
Phenhydan ${ }^{\circ}$ Afterwards, the cells were washed with icecold PBS and stained with $1 \mu \mathrm{g} / \mathrm{ml} \mathrm{CTxB}$ conjugated with Alexa Fluor ${ }^{\mathrm{TM}} 594$ in PBS for $10 \mathrm{~min}$ at $4{ }^{\circ} \mathrm{C}$ in the dark. Then, the cells were washed three times with PBS, and an $\alpha$-CTxB antibody (1:200) was added for $15 \mathrm{~min}$ at $4{ }^{\circ} \mathrm{C}$ in the dark to crosslink the CTxB in the lipid rafts. Subsequently, the cells were washed three times with ice-cold PBS and fixated with $4 \%$ paraformaldehyde for $10 \mathrm{~min}$ at room temperature in the dark, washed again and resuspended in PBS for the flow cytometer analysis.

\section{Statistical methods and analyses}

For all experiments, the differences between datasets were considered statistically significant when $p$-values were $<0.05$, if not otherwise specified. Statistical comparisons were performed using the two-tailed Student's $t$ test. Asterisks are used in the figures to specify statistical significance $(* p<0.05 ; * * p<0.02 ; * * * p<0.001)$. The results are presented as means \pm SD unless otherwise specified.

Acknowledgements We thank Maike Berger, Janina Kahl, Katja Bruch, and Parvin Davarnia for excellent technical assistance. We also thank the former lab member Federica De Zen, who contributed to the concept at the initial phase of the study. SK is supported by a grant provided by the Deutsche Forschungsgemeinschaft (DFG, German Research Foundation, Projektnummer: 400339789 [KR 1690/6-1]). This work was additionally funded by the Medical Faculty of CAU Kiel, Germany (to CM and SK), and Dr. Werner Jackstädt-Stiftung (to SK). AVJ is supported by an Australian Government Research Training Program Scholarship. JG is supported by the Fondation pour la recherche Médicale (FRM-ARF20170938613) and the Institute of Cardiometabolism and Nutrition (ICAN-PAP17NCEJG). JMM acknowledges funding from the National Health and Medical Research Council of Australia (1124735, 1105754, and IRIISS 9000433) and Victorian Government Operational Infrastructure Support. The Meier lab is supported by a World Wide Cancer Research grant (14-1328) and Breast Cancer Now CTR-QR14-007. PM acknowledges NHS funding to the NIHR Biomedical Research Centre and from the ERC (grant agreement no. 323040).

Author contributions SK and CM designed the research. CM, IJ, CD, TM, AVJ, JG, JF, JS, JHB, and CG performed the experiments. CM, JMM, UK, and SK analyzed the data. CM prepared the figures, SK and PM wrote the paper.

\section{Compliance with ethical standards}

Conflict of interest The authors declare that they have no conflict of interest.

Open Access This article is licensed under a Creative Commons Attribution 4.0 International License, which permits use, sharing, adaptation, distribution and reproduction in any medium or format, as long as you give appropriate credit to the original author(s) and the source, provide a link to the Creative Commons license, and indicate if changes were made. The images or other third party material in this article are included in the article's Creative Commons license, unless indicated otherwise in a credit line to the material. If material is not included in the article's Creative Commons license and your intended use is not permitted by statutory regulation or exceeds the permitted use, you will need to obtain permission directly from the copyright holder. To view a copy of this license, visit http://creativecommons. org/licenses/by/4.0/.

\section{References}

1. Fuchs Y, Steller H. Programmed cell death in animal development and disease. Cell. 2011;147:742-58.

2. Chan FK, Luz NF, Moriwaki K. Programmed necrosis in the cross talk of cell death and inflammation. Annu Rev Immunol. 2015;33:79-106.

3. Cho YS, Challa S, Moquin D, Genga R, Ray TD, Guildford M, et al. Phosphorylation-driven assembly of the RIP1-RIP3 complex regulates programmed necrosis and virus-induced inflammation. Cell. 2009;137:1112-23.

4. He S, Wang L, Miao L, Wang T, Du F, Zhao L, et al. Receptor interacting protein kinase-3 determines cellular necrotic response to TNF-alpha. Cell. 2009; 137:1100-11.

5. Zhang DW, Shao J, Lin J, Zhang N, Lu BJ, Lin SC, et al. RIP3, an energy metabolism regulator that switches TNF-induced cell death from apoptosis to necrosis. Science. 2009;325:332-6.

6. Sun L, Wang H, Wang Z, He S, Chen S, Liao D, et al. Mixed lineage kinase domain-like protein mediates necrosis signaling downstream of RIP3 kinase. Cell. 2012;148:213-27.

7. Kaiser WJ, Sridharan H, Huang C, Mandal P, Upton JW, Gough PJ, et al. Toll-like receptor 3-mediated necrosis via TRIF, RIP3, and MLKL. J Biol Chem. 2013;288:31268-79.

8. Robinson N, McComb S, Mulligan R, Dudani R, Krishnan L, Sad $\mathrm{S}$. Type I interferon induces necroptosis in macrophages during infection with Salmonella enterica serovar Typhimurium. Nat Immunol. 2012;13:954-62.

9. Wang X, Li Y, Liu S, Yu X, Li L, Shi C, et al. Direct activation of RIP3/MLKL-dependent necrosis by herpes simplex virus 1 (HSV1) protein ICP6 triggers host antiviral defense. Proc Natl Acad Sci USA. 2014;111:15438-43.

10. He S, Huang S, Shen Z. Biomarkers for the detection of necroptosis. Cell Mol Life Sci. 2016;73:2177-81.

11. Degterev A, Huang Z, Boyce M, Li Y, Jagtap P, Mizushima N, et al. Chemical inhibitor of nonapoptotic cell death with therapeutic potential for ischemic brain injury. Nat Chem Biol. 2005;1: $112-9$.

12. Takahashi N, Duprez L, Grootjans S, Cauwels A, Nerinckx W, DuHadaway JB, et al. Necrostatin-1 analogues: critical issues on the specificity, activity and in vivo use in experimental disease models. Cell Death Dis. 2012;3:e437.

13. Kearney CJ, Cullen SP, Clancy D, Martin SJ. RIPK1 can function as an inhibitor rather than an initiator of RIPK3-dependent necroptosis. FEBS J. 2014;281:4921-34.

14. Harris PA, Berger SB, Jeong JU, Nagilla R, Bandyopadhyay D, Campobasso N, et al. Discovery of a first-in-class receptor interacting protein 1 (RIP1) kinase specific clinical candidate (GSK2982772) for the treatment of inflammatory diseases. J Med Chem. 2017;60:1247-61.

15. Dondelinger Y, Declercq W, Montessuit S, Roelandt R, Goncalves A, Bruggeman I, et al. MLKL compromises plasma membrane integrity by binding to phosphatidylinositol phosphates. Cell Rep. 2014;7:971-81.

16. Fauster A, Rebsamen M, Huber KV, Bigenzahn JW, Stukalov A, Lardeau $\mathrm{CH}$, et al. A cellular screen identifies ponatinib and pazopanib as inhibitors of necroptosis. Cell Death Dis. 2015;6: e1767.

17. Newton K, Dugger DL, Wickliffe KE, Kapoor N, de Almagro $\mathrm{MC}$, Vucic D, et al. Activity of protein kinase RIPK3 determines 
whether cells die by necroptosis or apoptosis. Science. 2014;343:1357-60.

18. Raju S, Whalen DM, Mengistu M, Swanson C, Quinn JG, Taylor $\mathrm{SS}$, et al. Kinase domain dimerization drives RIPK3-dependent necroptosis. Sci Signal 2018;11:pii: eaar2188.

19. Mandal P, Berger SB, Pillay S, Moriwaki K, Huang C, Gou H, et al. RIP3 induces apoptosis independent of pronecrotic kinase activity. Mol Cell. 2014;56:481-95.

20. Kaushik NK, Kaushik N, Attri P, Kumar N, Kim CH, Verma AK, et al. Biomedical importance of indoles. Molecules. 2013;18:6620-62.

21. Johannessen SI, Landmark CJ. Antiepileptic drug interactions principles and clinical implications. Curr Neuropharmacol. 2010;8:254-67.

22. Müller T, Dewitz C, Schmitz J, Schröder AS, Bräsen JH, Stockwell BR, et al. Necroptosis and ferroptosis are alternative cell death pathways that operate in acute kidney failure. Cell Mol Life Sci. 2017;74:3631-45.

23. Zhang Y, Su SS, Zhao S, Yang Z, Zhong CQ, Chen X, et al. RIP1 autophosphorylation is promoted by mitochondrial ROS and is essential for RIP3 recruitment into necrosome. Nat Commun. 2017;8:14329.

24. Hunter I, Nixon GF. Spatial compartmentalization of tumor necrosis factor (TNF) receptor 1-dependent signaling pathways in human airway smooth muscle cells. Lipid rafts are essential for TNF-alpha-mediated activation of RhoA but dispensable for the activation of the NF-kappaB and MAPK pathways. J Biol Chem. 2006;281:34705-15.

25. Bieberich E. Sphingolipids and lipid rafts: Novel concepts and methods of analysis. Chem Phys Lipids. 2018;216:114-31.

26. Margheri G, D'Agostino R, Trigari S, Sottini S, Del RM. The beta-subunit of cholera toxin has a high affinity for ganglioside GM1 embedded into solid supported lipid membranes with a lipid raft-like composition. Lipids. 2014;49:203-6.

27. Schneider-Brachert W, Heigl U, Ehrenschwender M. Membrane trafficking of death receptors: implications on signalling. Int J Mol Sci. 2013;14:14475-503.

28. Sasaki Y, Oshima Y, Koyama R, Maruyama R, Akashi H, Mita H, et al. Identification of flotillin-2, a major protein on lipid rafts, as a novel target of p53 family members. Mol Cancer Res. 2008;6:395-406.

29. Veldman RJ, Maestre N, Aduib OM, Medin JA, Salvayre R, Levade T. A neutral sphingomyelinase resides in sphingolipidenriched microdomains and is inhibited by the caveolinscaffolding domain: potential implications in tumour necrosis factor signalling. Biochem J. 2001;355:859-68.

30. Lotocki G, Alonso OF, Dietrich WD, Keane RW. Tumor necrosis factor receptor 1 and its signaling intermediates are recruited to lipid rafts in the traumatized brain. J Neurosci. 2004;24: 11010-6.

31. Mahammad S, Parmryd I. Cholesterol depletion using methylbeta-cyclodextrin. Methods Mol Biol. 2015;1232:91-102.

32. Grosse PY, Bressolle F, Pinguet F. Antiproliferative effect of methyl-beta-cyclodextrin in vitro and in human tumour xenografted athymic nude mice. Br J Cancer. 1998;78:1165-9.

33. Blasius AL, Beutler B. Intracellular toll-like receptors. Immunity. 2010;32:305-15.

34. He S, Liang Y, Shao F, Wang X. Toll-like receptors activate programmed necrosis in macrophages through a receptorinteracting kinase-3-mediated pathway. Proc Natl Acad Sci USA. 2011;108:20054-9.
35. Wang H, Sun L, Su L, Rizo J, Liu L, Wang LF, et al. Mixed lineage kinase domain-like protein MLKL causes necrotic membrane disruption upon phosphorylation by RIP3. Mol Cell. 2014;54:133-46.

36. Tanzer MC, Matti I, Hildebrand JM, Young SN, Wardak A, Tripaydonis A, et al. Evolutionary divergence of the necroptosis effector MLKL. Cell Death Differ. 2016;23:1185-97.

37. Petrie EJ, Sandow JJ, Jacobsen AV, Smith BJ, Griffin MDW, Lucet IS, et al. Conformational switching of the pseudokinase domain promotes human MLKL tetramerization and cell death by necroptosis. Nat Commun. 2018;9:2422.

38. Tanzer MC, Tripaydonis A, Webb AI, Young SN, Varghese LN, Hall C, et al. Necroptosis signalling is tuned by phosphorylation of MLKL residues outside the pseudokinase domain activation loop. Biochem J. 2015;471:255-65.

39. Linkermann A, Bräsen JH, Darding M, Jin MK, Sanz AB, Heller $\mathrm{JO}$, et al. Two independent pathways of regulated necrosis mediate ischemia-reperfusion injury. Proc Natl Acad Sci USA. 2013;110:12024-9.

40. Günther C, He GW, Kremer AE, Murphy JM, Petrie EJ, Amann $\mathrm{K}$, et al. The pseudokinase MLKL mediates programmed hepatocellular necrosis independently of RIPK3 during hepatitis. J Clin Invest. 2016;126:4346-60.

41. Bonventre JV, Yang L. Cellular pathophysiology of ischemic acute kidney injury. J Clin Invest. 2011;121:4210-21.

42. Tiegs G, Hentschel J, Wendel AA. T cell-dependent experimental liver injury in mice inducible by concanavalin A. J Clin Invest. 1992;90:196-203.

43. Li Y, Qian L, Yuan J. Small molecule probes for cellular death machines. Curr Opin Chem Biol. 2017;39:74-82.

44. Fischer R, Marsal J, Gutta C, Eisler SA, Peters N, Bethea JR, et al. Novel strategies to mimic transmembrane tumor necrosis factordependent activation of tumor necrosis factor receptor 2. Sci Rep. 2017;7:6607.

45. Hueber AO, Bernard AM, Herincs Z, Couzinet A, He HT. An essential role for membrane rafts in the initiation of Fas/CD95-triggered cell death in mouse thymocytes. EMBO Rep. 2002;3:190-6.

46. Song JH, Tse MC, Bellail A, Phuphanich S, Khuri F, Kneteman $\mathrm{NM}$, et al. Lipid rafts and nonrafts mediate tumor necrosis factor related apoptosis-inducing ligand induced apoptotic and nonapoptotic signals in non small cell lung carcinoma cells. Cancer Res. 2007;67:6946-55.

47. Vanoosten RL, Moore JM, Ludwig AT, Griffith TS. Depsipeptide (FR901228) enhances the cytotoxic activity of TRAIL by redistributing TRAIL receptor to membrane lipid rafts. Mol Ther. 2005;11:542-52.

48. Chamberlain LH. Detergents as tools for the purification and classification of lipid rafts. FEBS Lett. 2004;559:1-5.

49. Ingolfsson HI, Sanford RL, Kapoor R, Andersen OS. Gramicidinbased fluorescence assay; for determining small molecules potential for modifying lipid bilayer properties. J Vis Exp. 2010;13; pii: 2131. https://doi.org/10.3791/2131.

50. Edelmann B, Bertsch U, Tchikov V, Winoto-Morbach S, Perrotta C, Jakob M, et al. Caspase- 8 and caspase-7 sequentially mediate proteolytic activation of acid sphingomyelinase in TNF-R1 receptosomes. EMBO J. 2011;30:379-94.

51. Murphy JM, Czabotar PE, Hildebrand JM, Lucet IS, Zhang JG, Alvarez-Diaz S, et al. The pseudokinase MLKL mediates necroptosis via a molecular switch mechanism. Immunity. 2013;39:443-53. 